\title{
Elongational deformation of wormlike micellar solutions
}

Dirk Sachsenheimer, Claude Oelschlaeger, Sonja Müller, Jan Küstner, Sebastian Bindgen, and Norbert Willenbacher

Citation: Journal of Rheology (1978-present) 58, 2017 (2014); doi: 10.1122/1.4897965 View online: http://dx.doi.org/10.1122/1.4897965

View Table of Contents: http://scitation.aip.org/content/sor/journal/jor2/58/6?ver=pdfcov Published by the The Society of Rheology

\section{Articles you may be interested in}

Nanodiamond gels in nonpolar media: Colloidal and rheological properties

J. Rheol. 58, 1599 (2014); 10.1122/1.4892901

Molecular dynamics study on effect of elongational flow on morphology of immiscible mixtures

J. Chem. Phys. 140, 134902 (2014); 10.1063/1.4869404

Realization of freestanding wrinkled thin films with flexible deformability Appl. Phys. Lett. 98, 041908 (2011); 10.1063/1.3549203

Filament stretching and capillary breakup extensional rheometry measurements of viscoelastic wormlike micelle solutions

J. Rheol. 51, 693 (2007); 10.1122/1.2718974

Rheological properties and foaming behavior of polypropylenes with different molecular structures

J. Rheol. 50, 907 (2006); 10.1122/1.2351880

\section{Re-register for Table of Content Alerts}




\title{
Elongational deformation of wormlike micellar solutions
}

\author{
Dirk Sachsenheimer, ${ }^{\text {a) }}$ Claude Oelschlaeger, Sonja Müller, Jan Küstner, \\ Sebastian Bindgen, and Norbert Willenbacher
Karlsruhe Institute of Technology (KIT), Institute for Mechanical Process Engineering and Mechanics, Group Applied Mechanics (AME), Gotthard-Franz-Straße 3, 76131 Karlsruhe, Germany

(Received 8 July 2014; final revision received 25 September 2014; published 24 October 2014)

\begin{abstract}
Synopsis
We have investigated the uniaxial elongation behavior of six different wormlike micelle systems covering a broad range of surfactant concentrations $c_{s}$ and salt/surfactant ratios $R$ using the capillary breakup elongational rheometry (CaBER). In the fast-breaking limit (high $\mathrm{c}_{\mathrm{s}}$ and $\mathrm{R}$ ), filament lifetime $t_{\text {fil }}$ is controlled by the equilibrium shear modulus $G_{0}$ and the breakage time $\lambda_{\text {br }}$ obtained from small oscillatory shear according to $t_{\text {fil }} / G_{0} \propto \lambda_{b r}^{2 / 3}$ and relaxation time ratios $\lambda_{\mathrm{e}} / \lambda_{\mathrm{s}} \approx 1$ are found. When reptation dominates (high $\mathrm{c}_{\mathrm{s}}$, low $\mathrm{R}$ ) $\lambda_{\mathrm{e}} / \lambda_{\mathrm{s}}<1$ is observed similar as for solutions of covalently bound polymers. In this concentration regime, the micellar structure seems not to be affected by the strong elongational flow. In contrast, high filament lifetimes up to $1000 \mathrm{~s}$ and $\lambda_{\mathrm{e}} / \lambda_{\mathrm{s}}$ values up to 10 are observed at low $\mathrm{c}_{\mathrm{s}}$ irrespective of $\mathrm{R}$. This indicates the formation of elongation-induced structures (EISs). A minimum viscosity and a minimum initial diameter are required for creating EIS. Additional filament stretching experiments indicate that a critical total deformation has to be exceeded for structure build-up. Finally, our experiments reveal a distinct difference regarding the dependence between solutions of linear and branched micelles of filament lifetime on viscosity suggesting that CaBER is a versatile means to distinguish between these structures. (C) 2014 The Society of Rheology. [http://dx.doi.org/10.1122/1.4897965]
\end{abstract}

\section{INTRODUCTION}

\section{A. General remarks}

Surfactant solutions forming wormlike micelles (WLMs) are widely used in home and personal care products (e.g., cosmetics and detergents) [Yang (2002)] and are becoming increasingly important in, e.g., enhanced oil recovery [Padding et al. (2009)], agrochemical spraying [Xue et al. (2008)], and drag reduction agents [Arora et al. (2002); Li et al. (2008); Hadri and Guillou (2010)]. Respective applications involve complex flow kinematics with strong extensional components, which can cause large and rapid deformation of the fluid microstructure. The resulting stretching and alignment of micelles lead to a range of unconventional phenomena including flow-induced chain scission [Vasquez et al. (2007); Germann et al. (2013)], structure formation [Vasudevan et al. (2010)], and

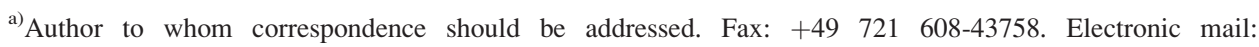
sachsenheimer@kit.edu
} 
elastic instabilities [Pathak and Hudson (2006)]. A fundamental understanding of material properties as well as the ability to predict changes that occur within the material during processing is extremely important for industrial application. Investigations so far mainly focused on the shear-banding phenomenon [Britton and Callaghan (1997); Britton and Callaghan (1999); Haward and McKinley (2012); Fischer and Challaghan (2001); Salmon et al. (2003)], shear-thickening even in dilute solutions [Hu and Matthys (1995); Cappelaere et al. (1994); Hartmann and Cressely (1997a); Hartmann and Cressely (1997b); Hartmann and Cressely (1997c); Cressely and Hartmann (1998); Hartmann and Cressely (1998); Wheeler et al. (1998); Hu et al. (1998); Nowak (2001); Berret and Serero (2001); Azzouzi et al. (2005); Vasudevan et al. (2008)] and the corresponding shear-induced structure (SIS) [Wheeler et al. (1996); Kadoma et al. (1997); Ouchi et al. (2006a); Ouchi et al. (2006b)] using different techniques such as turbidity [Yamamoto and Taniguchi (2012); Schubert et al. (2004); Lerouge et al. (2008); Herle et al. (2005)], flow birefringence [Dehmoune et al. (2007); Berret et al. (2002); Wunderlich et al. (1987); Oda et al. (1997); Ouchi et al. (2006b)], light scattering [Liu and Pine (1996); Boltenhagen et al. (1997)], cryo transmission electron microscopy (cryo-TEM) [Oda et al. (1997); Lu et al. (1998)], particle image velocimetry [Hu et al. (1998)], and small-angle neutron scattering [Hoffmann et al. (1991); Schmitt et al. (1995); Berret et al. (1998); Münch et al. (1993); Herle et al. (2007); Dehmoune et al. (2009); Lutz-Bueno et al. (2013)]. This structure formation phenomenon has been mainly investigated for surfactant systems composed of CTAB/NaSal [Hu et al. (1994); Liu and Pine (1996); Shikata et al. (1988); Kadoma and van Egmond (1998); Humbert and Decruppe (1998); Vasudevan et al. (2008); Dehmoune et al. (2009); Lutz-Bueno et al. (2013)] and $\mathrm{CPyCl} / \mathrm{NaSal}$ [Wheeler et al. (1998); Fischer et al. (2002); Callaghan et al. (1996); Mair and Callaghan (1997); Britton and Callaghan (1999); Schmitt et al. (1994)] but so far this effect is not yet fully understood and very little is known about extensional thickening and structure formation in extensional flow.

In this study, we use capillary breakup elongational rheometry (CaBER) to get a deeper insight into the rheological behavior and flow-induced structural change of WLM solutions in uniaxial elongational flow. In particular, two aspects are covered. In the first part of this paper, general observations of filament formation and subsequent thinning of WLM solutions are discussed in detail. In the second part, elongational material properties, such as filament lifetime and elongational relaxation time, are related to corresponding shear parameters and the occurrence of elongation-induced structures (EISs) is discussed in detail. Prior to presenting our results, we describe the state of art regarding the behavior of WLM solutions in elongational flows particularly focusing on the CaBER method and its application to WLM systems. We finish this paper with a short conclusion.

\section{B. Capillary breakup extensional rheometry}

In CaBER experiments [Bazilevsky et al. (1990); Entov and Hinch (1997); Bazilevsky et al. (2001); McKinley (2005)], a fluid drop is placed between two plates and subsequently exposed to an extensional step strain thus forming an unstable liquid filament. The following thinning process of the fluid filament is driven by capillary stresses and resisted by viscous and/or elastic stresses developed in the liquid thread during flow. The CaBER technique can be applied to liquids covering a wide range of viscosities, from about $50 \mathrm{mPas}$ up to 100 Pas. The technique is straightforward, fast and requires only a small amount of sample $(\mathrm{V}<0.1 \mathrm{ml})$ and, in contrast to other techniques, CaBER allows 
for large Hencky strains up to $\varepsilon=10$ which are of great significance to technical applications.

In the common CaBER setup, the only measured quantity during filament thinning is the diameter decay $\mathrm{D}(\mathrm{t})$ at a single position in the filament. However, different extensions are reported in the literature such as optical shape recognition using a high-speed camera [Christanti and Walker (2001a); Niedzwiedz et al. (2009); Nelson et al. (2011); Gier and Wagner (2012); Sattler et al. (2012)], force measurement during initial step strain [Klein et al. (2009)] as well as during the whole capillary thinning process [Sachsenheimer et al. (2012)]. Recently, also a temperature control option has been presented allowing for a uniform temperature distribution within the filament [Sachsenheimer et al. (submitted)].

The thinning behavior strongly depends on the type of material. Different characteristic diameter vs time curves are reported in the literature [McKinley (2005)]. For Newtonian fluids, a slightly noncylindrical filament shape is observed and the corresponding minimum diameter decreases linearly according to [Papageorgiou (1995); McKinley and Tripathi (2000); Sachsenheimer et al. (2012)]

$$
\mathrm{D}(\mathrm{t})=\mathrm{D}_{1}-0.1418 \frac{\Gamma}{\eta_{0}} \mathrm{t},
$$

where $\Gamma$ is the surface tension, $\eta_{0}$ is the viscosity of the Newtonian fluid, and $D_{1}$ is the diameter at the beginning of the linear decay. For viscoelastic fluids such as polymer solutions [Bazilevsky et al. (1990); Entov and Hinch (1997); Anna and McKinley (2001); Arnolds et al. (2010); Clasen (2010); Sachsenheimer et al. (2012); Sachsenheimer et al. (submitted)] or surfactant solutions [Yesilata et al. (2006); Bhardwaj et al. (2007b); Chellamuthu and Rothstein (2008); Miller et al. (2009); Kim et al. (2010); Sachsenheimer et al. (submitted)], cylindrical filaments are observed and at least in a certain stage of thinning the diameter decreases exponentially with time according to

$$
\mathrm{D}(\mathrm{t}) \propto \exp \left(-\frac{\mathrm{t}}{3 \lambda_{\mathrm{e}}}\right),
$$

where $\lambda_{\mathrm{e}}$ is the elongational relaxation time. Differences between this elongational relaxation time and the characteristic shear relaxation time $\lambda_{\mathrm{s}}$ obtained from small amplitude oscillatory shear (SAOS) are related to the strong nonlinear deformation in CaBER experiments [Arnolds et al. (2010); Sachsenheimer et al. (submitted)]. The exponential diameter decay directly corresponds to an exponentially increasing viscosity which has its physical origin in the loss of entropy during stretching of, e.g., polymer molecules or wormlike micellar structures.

\section{Elongational flow of WLM solutions}

The elongational rheology of WLM solutions is, up to now, poorly understood. Early investigations were based on opposed jet experiments [Fischer et al. (1997); Lu et al. (1998); Prud'homme and Warr (1994); Walker et al. (1996); Chen and Warr (1997)], four-roll mill experiments [Kato et al. (2002); Kato et al (2004); Kato et al. (2006)], entrance flow [Okawara et al. (2008); Okawara et al. (2009)], two-dimensional squeeze flow [Takahashi and Sakata (2001)], and flow through porous media experiments [Muller et al. (2004)] showing an elongational hardening (increase of elongational viscosity with increasing elongation rate) of WLM solutions which is attributed to strong alignment of 
the micelles in flow direction. However, all these experiments were not purely extensional or had an unknown preshear history.

Recently, extensional rheology of WLM has been investigated using continuous filament stretching [Filament stretching extensional rheometer (FiSER)] or capillary thinning (CaBER) experiments [Rothstein (2003); Yesilata et al. (2006); Bhardwaj et al. (2007b); Bhardwaj et al. (2007a); Chellamuthu and Rothstein (2008); Miller et al. (2009); Kim et al. (2010); Sachsenheimer et al. (submitted)] which allow for applying a purely extensional flow field to these low viscosity liquids.

Yesilata et al. (2006) have used the CaBER method to measure the extensional behavior of erucyl bis(hydroxyethyl)methylammonium chloride (EHAC) and isopropanol in a brine of ammonium chloride in deionized water. These solutions clearly form exponentially thinning cylindrical filaments. The elongational relaxation time $\lambda_{\mathrm{e}}$ was about a factor of three lower than the longest relaxation time $\lambda_{\mathrm{s}}$ calculated from SAOS measurements. This is different from CaBER results for Boger fluids, where $\lambda_{\mathrm{e}} \approx \lambda_{\mathrm{s}}$ was found [Anna and McKinley (2001)] but similar to concentrated polymer solutions [Oliveira et al. (2006); Arnolds et al. (2010); Clasen (2010); Sachsenheimer et al. (submitted)]. Later $\mathrm{CaBER}$ measurements for a series of $\mathrm{CTAB} / \mathrm{NaSal}$ solutions showed that the ratio of the extensional relaxation time and the shear relaxation time $\lambda_{\mathrm{e}} / \lambda_{\mathrm{s}}$ starts at values less than one $\left(\lambda_{\mathrm{e}} / \lambda_{\mathrm{s}}=0.5\right)$ and increases linearly with increasing surfactant concentration, eventually reaching a plateau at roughly $\lambda_{\mathrm{e}} / \lambda_{\mathrm{s}} \approx 1$ [Bhardwaj et al. (2007b)]. The onset of the plateau corresponds approximately to the surfactant concentration, where a maximum in zero-shear viscosity is observed for a given salt/surfactant ratio. For $\mathrm{CPyCl} /$ NaSal solutions, $\lambda_{\mathrm{e}} / \lambda_{\mathrm{s}}$ also begins at a value much less than one $\left(\lambda_{\mathrm{e}} / \lambda_{\mathrm{s}}=0.2\right)$ and then monotonically increases with increasing surfactant concentration but without reaching a plateau value at large surfactant concentrations.

The only study addressing the role of branching on the extensional rheology of WLM has been performed by Chellamuthu and Rothstein (2008). For a series of linear and branched WLM solutions of sodium oleate (NaOA) and octyltrimethyl ammonium bromide $\left(\mathrm{C}_{8} \mathrm{TAB}\right)$, these authors observe a dramatic decrease of relaxation time ratio $\lambda_{\mathrm{e}} / \lambda_{\mathrm{s}}$ in CaBER and a maximum Trouton ratio in FiSER with the onset of branching. They hypothesize that this is due to the additional stress relief mechanisms caused by sliding or ghostlike crossing effects which are supposed to be more efficient in elongational flows. This study suggests that transient extensional rheology might be suitable to distinguish between branched and linear micelles. Other mechanical techniques are so far not available for differentiating branched WLM solutions from linear entangled micelle solutions [Decruppe and Ponton (2003)]. Also in neutron or light scattering experiments, linear micelles and branched micelles show similar behavior. So far, the only method that can directly distinguish linear and branched micelles is cryo-TEM [Clausen et al. (1992); Danino et al. (2000); Danino et al. (2001); Croce et al. (2003); Ziserman et al. (2004); Abezgauz and Danino (2007); Helgeson et al. (2010); Danino (2012)]. All these studies have indicated that the first viscosity maximum occurring at a critical salt/surfactant ratio $R_{\max }$ is attributed to the transition from linear to branched micelles.

Using the CaBER technique, Sachsenheimer et al. (submitted) recently reported a detailed analysis of $\mathrm{CPyCl} / \mathrm{NaSal}(\mathrm{R}=0.5)$ dissolved in aqueous solution of $500 \mathrm{mM}$ sodium chloride $(\mathrm{NaCl})$. These solutions with different surfactant concentrations between $40 \mathrm{mM}$ and $120 \mathrm{mM}$ show an intermediate Newtonian thinning region followed by viscoelastic thinning indicated by a change of the dimensionless fore ratio from $\mathrm{X}=0.713$ to $\mathrm{X}=1$, where $\mathrm{X}=\mathrm{F} / \pi \Gamma \mathrm{D}$ is defined as the ratio of the true axial force $\mathrm{F}$ in the filament and the force due to surface tension $(\pi \Gamma \mathrm{D})$. The exponential diameter decay allows for a robust determination of the elongational relaxation time $\lambda_{\mathrm{e}}$, and a relaxation time ratio 
$\lambda_{\mathrm{e}} / \lambda_{\mathrm{s}} \approx 1$ was found independent of surfactant concentration. This indicates that the equilibrium conformation of the WLM is not affected by the strong elongational flow during capillary thinning.

There are only a few studies dealing with a structure build-up in elongational flows. Combining the opposed nozzle technique with small-angle light scattering (SALS), the apparent elongational viscosity and the radius of gyration $\mathrm{R}_{\mathrm{G}}$ in elongational direction of a WLM (TTAB/NaSal) solution were determined simultaneously. Both quantities exhibit a pronounced maximum upon variation of strain rate $\dot{\varepsilon}$ at the same critical value. The decrease of the elongational viscosity and $\mathrm{R}_{\mathrm{G}}$ is attributed to the scission of micelles as predicted theoretically [Vasquez et al. (2007); Cromer et al. (2009); Germann et al. (2013)]. However, it could not be resolved whether the increase in $\mathrm{R}_{\mathrm{G}}$ observed at low elongation rates is just due to alignment and elongation of micelles in flow direction or whether fusion of micelles occurs increasing the average micellar contour length [Chen and Warr (1997)]. Okawara et al. [Okawara et al. (2008); Okawara et al. (2009)] investigated the pressure loss $\Delta \mathrm{p}$ of $\mathrm{CTAB} / \mathrm{NaSal}$ solutions $\left(\mathrm{c}_{\mathrm{s}}=30 \mathrm{mM}\right)$ at high salt/surfactant ratios $\mathrm{R}$ flowing through two different converging channels and analyzed structural changes using simultaneous SALS experiments. For a distinct apparent elongation rate regime (regime II), a strong increase of $\Delta \mathrm{p}$ with increasing elongational rate has been observed. Corresponding SALS measurements show a combination of butterfly type and streak-type pattern indicating a structure build-up. A further increase of the apparent elongation rate (regime III) results in a weaker increase of $\Delta \mathrm{p}$ with increasing $\dot{\varepsilon}$ than in regime II and a change in the SALS patterns indicates a less pronounced structure build-up at these elevated elongation rates. Furthermore, the measurements of Okawara et al. show that the creation of EISs depends not only on the elongational rate but also on the total Hencky strain.

Takahashi et al. [Takahashi and Sakata (2011)] investigated the flow-induced structure build-up of similar $\mathrm{CTAB} / \mathrm{NaSal}$ solutions $\left(\mathrm{c}_{\mathrm{s}}=30 \mathrm{mM}, \mathrm{R}>1\right)$ in planar elongation using a squeeze flow device. In this setup, elongational deformation is dominant in the center plane whereas shear dominates close to the walls. Structure formation was verified by the occurrence of opaque regions during flow at the rim close to the walls (SIS) as well as in the center plane (EIS). SIS was observed at shorter elapsed times than EIS but at significantly higher critical strains and strain rates. Furthermore, the EISs occurred at a critical total strain $\varepsilon_{c}$ irrespective of the salt/surfactant ratio R but all solutions had $\mathrm{R}$ values corresponding to the fast-breaking limit (branched micelles). To our knowledge, these are the only studies directly showing structure build-up in elongational flow of WLM solutions.

In summary, the extensional flow properties of WLM solutions deserve further exploration. Despite some data in the literature [Bhardwaj et al. (2007b); Chellamuthu and Rothstein (2008)], a systematic investigation of extensional flow behavior as a function of $\mathrm{R}$ covering both viscosity maxima (if present) is still lacking and there are still uncertainties and questions that remain open. First, the variation and interpretation of the elongational relaxation time $\lambda_{\mathrm{e}}$ and its relation to the shear relaxation time $\lambda_{\mathrm{s}}$ as a function of surfactant or salt concentration are unclear. The question whether extensional rheology is able to distinguish between linear and branched micelles is also still open. Furthermore, the phenomenon of structure build-up during elongational flow is almost uninvestigated.

\section{EXPERIMENTAL SETUP AND SAMPLE PREPARATION}

\section{A. Capillary breakup extensional rheometry}

In our setup, the CaBER-1 (Thermo Scientific, Karlsruhe) is extended with an optical train, including a high-speed camera (Photron Fastcam-X 1024 PCI) as well as a 
telecentric objective (MaxxVision TC4M 16, magnification: $\mathrm{x} 1$ ) and blue telecentric backlight illumination (Vision \& Control TZB30-B), allowing for full filament assessment with high spatial and temporal resolution of $16 \mu \mathrm{m} / \mathrm{px}$ and up to $3000 \mathrm{fps}$. In case of very stable filaments, the high-speed camera has been replaced by a PIKE CCD camera (Allied Vision Technologies) achieving a frame rate of $10 \mathrm{fps}$. Further details about the experimental setup and the data analysis are given in Niedzwiedz et al. (2009) and Sachsenheimer et al. (2012). A representative sketch of the experiment can be found, e.g., in Bhardwaj et al. (2007b). Plates with a diameter $\mathrm{D}=6 \mathrm{~mm}$ are used in all experiments. Filaments are stretched from $h_{i}=1.5 \mathrm{~mm}$ to $h_{f}=6 \mathrm{~mm}$ within a strike time of $\mathrm{t}_{\mathrm{s}}=40 \mathrm{~ms}$ as discussed in Sec. III A. Our customized temperature control unit [Sachsenheimer et al. (submitted)] was used for measurements at elevated temperatures. Furthermore, this unit providing a saturated atmosphere thus preventing solvent evaporation was used for measurements of solutions showing high filament lifetimes.

\section{B. Filament stretching extensional rheometer}

Liquid filaments were stretched continuously using the home made FiSER setup of Professor Rothstein of the University of Massachusetts [Anna et al. (2001); Rothstein and McKinley (2002a); Rothstein and McKinley (2002b); Rothstein (2003)]. Plates with a diameter $\mathrm{D}=5 \mathrm{~mm}$ and an initial displacement $\mathrm{L}_{0}=0.75 \mathrm{~mm}$ were separated with increasing speed in order to achieve a constant stretching rate according to

$$
\dot{\varepsilon}_{\mathrm{L}}=\frac{1}{\mathrm{~L}} \frac{\mathrm{dL}}{\mathrm{dt}} .
$$

A metal grid was glued onto the plates to increase the adhesion between plates and liquids under test. The diameter vs time curve was recorded using a laser micrometer. Unfortunately, axial forces were too low so that only the evolution of $\mathrm{D}(\mathrm{t})$ could be recorded. Filament stretching experiments were performed at room temperature of $25^{\circ} \mathrm{C} \pm 3{ }^{\circ} \mathrm{C}$.

\section{Shear rheology}

Steady shear experiments and SAOS were performed using a MARS II (Thermo Fischer, Karlsruhe, Germany) equipped with a cone plate fixture $\left(60 \mathrm{~mm}\right.$ diameter and $1^{\circ}$ cone angle) or a coaxial cylinder system (Z20 DIN) depending on sample viscosity.

Steady shear data were obtained in a shear rate range of $\dot{\gamma}=0.1-500 \mathrm{~s}^{-1}$. A sudden increase of viscosity occurring for $\mathrm{CTAB} / \mathrm{NaSal}$ and $\mathrm{CPyCl} / \mathrm{NaSal}$ solutions at a critical shear rate was taken as evidence for SIS formation, because these systems are well known to undergo structural formations during nonlinear deformation [Liu and Pine (1996); Wheeler et al. (1998); Herle et al. (2005); Ouchi et al. (2006b); Vasudevan et al. (2008); Takahashi and Sakata (2011); Lutz-Bueno et al. (2013].

The shear modulus $\mathrm{G}^{*}=\mathrm{G}^{\prime}+i \mathrm{G}^{\prime \prime}$ was obtained from SAOS experiments covering the frequency range $\omega=0.01-50 \mathrm{rad} / \mathrm{s}$. Based on these measurements, the terminal shear relaxation time and the zero-shear viscosity

$$
\lambda_{\mathrm{s}}=\lim _{\omega \rightarrow 0} \frac{\mathrm{G}^{\prime}}{\mathrm{G}^{\prime \prime} \omega} \quad \text { and } \quad \eta_{0}=\lim _{\omega \rightarrow 0} \frac{\mathrm{G}^{\prime \prime}}{\omega}
$$

were determined.

High frequency shear modulus data were obtained from oscillatory squeeze flow experiments using a piezo-driven axial vibrator (PAV) described in Crassous et al. (2005) and Oelschlaeger et al. (2009). These experiments cover the frequency range up to 
$\omega=50,000 \mathrm{rad} / \mathrm{s}$ and were used for a reliable assessment of the plateau modulus $\mathrm{G}_{0}$ and the breakage time $\lambda_{\mathrm{br}}=1 / \omega\left(G_{\mathrm{min}}^{\prime \prime}\right)$ [Fischer and Rehage (1997); Yesilata et al. (2006)].

\section{Additional techniques}

Surface tension $\Gamma$ has been determined for $\mathrm{CPyCl} / \mathrm{NaSal}$ and $\mathrm{CTAB} / \mathrm{NaSal}$ solutions with an experimental error of $\Delta \Gamma= \pm 1 \mathrm{mN} / \mathrm{m}$ using a DCAT1 tensiometer (DataPhysics, Filderstadt, Germany) equipped with a platinum-iridium Wilhelmy-plate at $\mathrm{T}=20^{\circ} \mathrm{C}$.

\section{E. Test fluids}

The surfactants hexadecyltrimethylammonium bromide (CTAB) and cetylpyridinium chloride $(\mathrm{CPyCl})$ as well as the salts sodium salicylate (NaSal), potassium bromide $(\mathrm{KBr})$, sodium nitrate $\left(\mathrm{NaNO}_{3}\right)$, sodium chlorate $\left(\mathrm{NaClO}_{3}\right)$, and sodium chloride $(\mathrm{NaCl})$ were purchased as powder with a purity of at least $98 \%$ from Carl Roth GmbH (Karlsruhe, Germany) and were used without further treatment. Surfactants and salt were dissolved in distilled water and homogenized by means of shaking for five days at room temperature. Solutions were then stored for another five days before measuring to ensure the formation of the equilibrium micelles structure. Solutions of $\mathrm{CPyCl} / \mathrm{NaSal}, \mathrm{CTAB} /$ $\mathrm{NaSal}, \mathrm{CTAB} / \mathrm{KBr}, \mathrm{CTAB} / \mathrm{NaNO}_{3}$, and $\mathrm{CTAB} / \mathrm{NaClO}_{3}$ were prepared at constant surfactant concentration but different salt/surfactant ratios $\mathrm{R}$ covering the dilute and semidilute regime. For the sake of clarity, it should be noted that all concentrations given in this paper refer to the concentration of the surfactant molecules and not to the total concentration of both, surfactant and salt. For selected $\mathrm{R}$ values, the systems $\mathrm{CPyCl} / \mathrm{NaSal}$ and $\mathrm{CTAB} / \mathrm{NaSal}$ were analyzed at different surfactant concentrations. In addition, $\mathrm{CPyCl} /$ $\mathrm{NaSal} / \mathrm{NaCl}$ solutions were prepared at a fixed $\mathrm{CPyCl} / \mathrm{NaSal}$ ratio of $\mathrm{R}=0.5$ with surfactant concentrations between $40 \mathrm{mM}$ and $120 \mathrm{mM}$ and a $\mathrm{NaCl}$ concentration of $500 \mathrm{mM}$ as described by Berret et al. (1993). Different measurement temperatures were applied in order to prevent crystallization of the surfactant solutions. Sample compositions and measurement temperatures are summarized in Table I.

Figure 1(a) shows the variation of the zero-shear viscosity $\eta_{0}$ as a function of salt/surfactant ratio R for WLM solutions with constant surfactant concentration investigated in this study. Corresponding values for $\mathrm{CPyCl} / \mathrm{NaSal} / \mathrm{NaCl}$ solutions are shown elsewhere [Berret et al. (1993)]. At low salt/surfactant ratios R, all systems show an increase of the zero-shear viscosity with increasing $\mathrm{R}$ in good agreement with earlier observations [e.g., the works of Rehage and Hoffmann (1988), Azzouzi et al. (2005), Oelschlaeger et al. (2009), and Oelschlaeger et al. (2010)]. At higher salt/surfactant ratios, differences between the different surfactant solutions occur. For $\mathrm{CPyCl} / \mathrm{NaSal}$ and $\mathrm{CTAB} / \mathrm{NaSal}$, the viscosity as a function of the salt/surfactant ratio $\mathrm{R}$ shows two maxima but only one broad viscosity maximum is observed for $\mathrm{CTAB} / \mathrm{NaClO}_{3}$. The systems $\mathrm{CTAB} / \mathrm{NaNO}_{3}$ and $\mathrm{CTAB} / \mathrm{KBr}$ show a monotonic increase of viscosity in the

TABLE I. Investigated salt/surfactant systems with measurement temperatures.

\begin{tabular}{lcc}
\hline \hline System & Surfactant concentration & Measurement temperature \\
\hline $\mathrm{CPyCl} / \mathrm{NaSal}$ & $5 \mathrm{mM}-100 \mathrm{mM}$ & $20^{\circ} \mathrm{C}$ \\
$\mathrm{CPyCl} / \mathrm{NaSal} / \mathrm{NaCl}$ & $40 \mathrm{mM}-120 \mathrm{mM}$ & $25^{\circ} \mathrm{C}$ \\
$\mathrm{CTAB} / \mathrm{NaSal}$ & $5 \mathrm{mM}-25 \mathrm{mM}$ & $20^{\circ} \mathrm{C}$ \\
$\mathrm{CTAB} / \mathrm{KBr}$ & $150 \mathrm{mM}$ & $35^{\circ} \mathrm{C}$ \\
$\mathrm{CTAB} / \mathrm{NaNO}_{3}$ & $75 \mathrm{mM}$ & $25^{\circ} \mathrm{C}$ \\
$\mathrm{CTAB} / \mathrm{NaClO}_{3}$ & $150 \mathrm{mM}$ & $30^{\circ} \mathrm{C}$ \\
\hline \hline
\end{tabular}



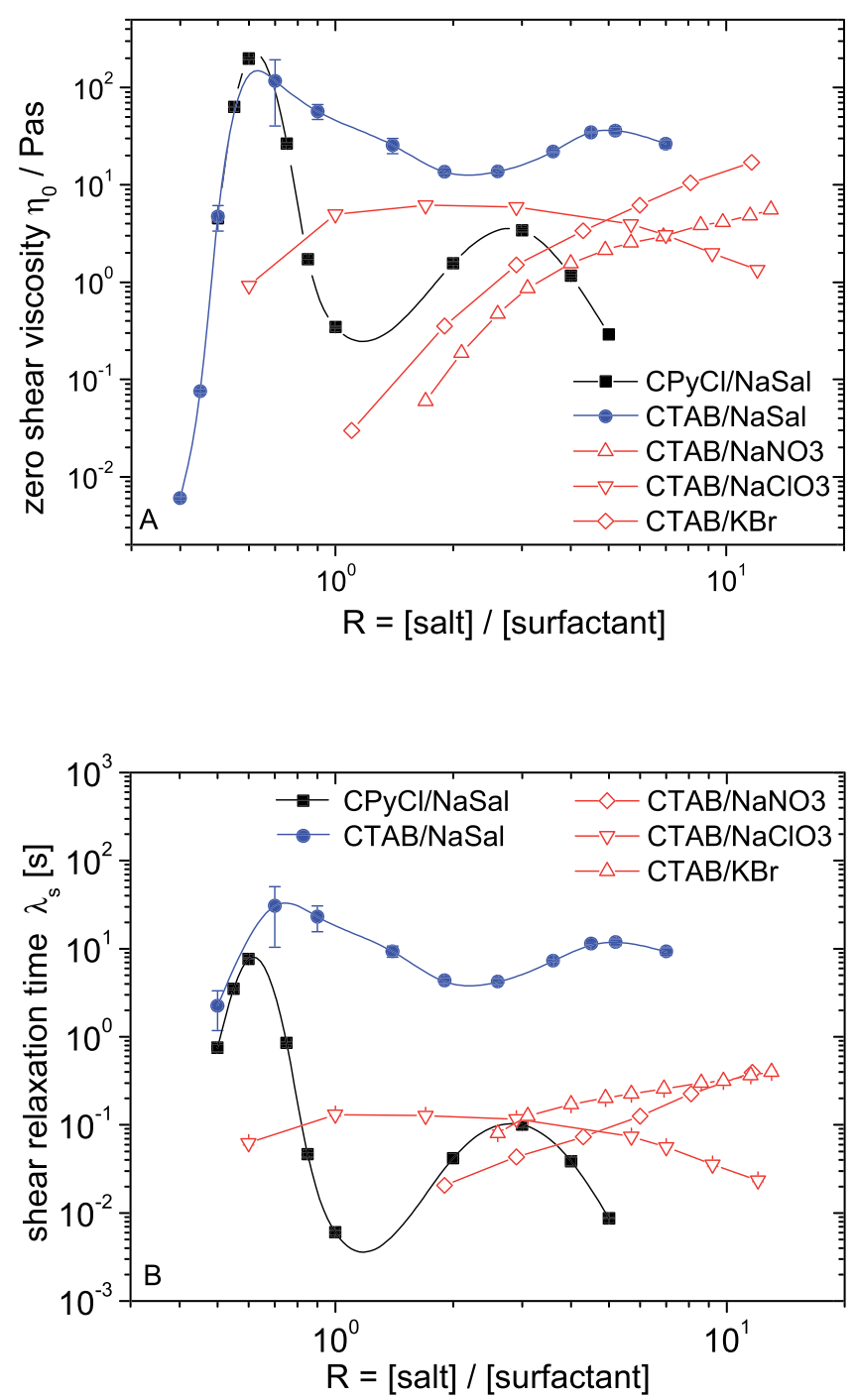

FIG. 1. Zero-shear viscosity $\eta_{0}$ (top) and terminal shear relaxation time $\lambda_{\mathrm{s}}$ (bottom) as a function of the salt/surfactant ratio $\mathrm{R}$ for $100 \mathrm{mM} \mathrm{CPyCl} / \mathrm{NaSal}$ (measurement temperature $\mathrm{T}=20^{\circ} \mathrm{C}$ ), $25 \mathrm{mM} \mathrm{CTAB} / \mathrm{NaSal}$ $\left(\mathrm{T}=20^{\circ} \mathrm{C}\right), 75 \mathrm{mM} \mathrm{CTAB} / \mathrm{NaNO}_{3}\left(\mathrm{~T}=25^{\circ} \mathrm{C}\right), 150 \mathrm{mM} \mathrm{CTAB} / \mathrm{NaClO}_{3}\left(\mathrm{~T}=30^{\circ} \mathrm{C}\right)$, and $150 \mathrm{mM} \mathrm{CTAB} / \mathrm{KBr}$ $\left(\mathrm{T}=35^{\circ} \mathrm{C}\right)$ solutions. Lines are to guide the eye.

investigated $\mathrm{R}$ range. For $\mathrm{CPyCl} / \mathrm{NaSal}$ and $\mathrm{CTAB} / \mathrm{NaSal}$ solutions, the first viscosity maximum occurs at the same salt/surfactant ratio of $\mathrm{R}_{\max }=0.6 \pm 0.1$. In order to study differences in capillary thinning at similar zero-shear viscosity $\eta_{0}$, the surfactant concentrations for these two systems were chosen such that $\eta_{0}$ values obtained for $\mathrm{R}<\mathrm{R}_{\max }$.

The shear relaxation time was analyzed in two different ways: The terminal shear relaxation time $\lambda_{\mathrm{s}}$ [Fig. 1(b)] calculated according to equation 4 and the crossover relaxation time $\lambda_{\mathrm{s}, \mathrm{c}}$ defined as the inverse of the crossover frequency at which $\mathrm{G}^{\prime}=\mathrm{G}^{\prime \prime}$. Shear relaxation time ratios $\lambda_{\mathrm{s}} / \lambda_{\mathrm{s}, \mathrm{c}}=1$ are found for solutions in the fast-breaking limit with $\mathrm{R}>\mathrm{R}_{\max }$, where $\mathrm{R}_{\max }$ denotes the salt/surfactant ratio at which the first viscosity maximum occurs. For $\mathrm{R}<\mathrm{R}_{\max }, \lambda_{\mathrm{s}}>\lambda_{\mathrm{s}, \mathrm{c}}$ is observed corresponding to a multiexponential decay of the shear stress. In the following, only the terminal shear relaxation time $\lambda_{\mathrm{s}}$ will 
be considered. However, for very low $\mathrm{R}$ values, the terminal flow region where $\mathrm{G}^{\prime} \propto \omega^{2}$ and $\mathrm{G}^{\prime \prime} \propto \omega$ could not be observed. In these cases, the zero-shear viscosity was determined from steady shear experiments but no $\lambda_{\mathrm{s}}$ values could be obtained.

\section{RESULTS AND DISCUSSION}

\section{A. Choice of step-strain parameters in CaBER experiments for WLM solutions}

The step-strain parameters initial gap height $h_{i}$, final gap height $h_{f}$, and strike time $t_{s}$ set in a CaBER experiment may have a strong effect on the subsequent capillary thinning process, since they determine the initial filament diameter as well as the axial stress within the filament.

In preliminary experiments, four different sets of $h_{i}$ and $h_{f}$ have been used $\left(\mathrm{h}_{\mathrm{i}}=0.5 \mathrm{~mm}\right.$ and $\mathrm{h}_{\mathrm{f}}=6 \mathrm{~mm}, \mathrm{~h}_{\mathrm{i}}=1.5 \mathrm{~mm}$ and $\mathrm{h}_{\mathrm{f}}=11 \mathrm{~mm}, \mathrm{~h}_{\mathrm{i}}=1.5 \mathrm{~mm}$ and $\mathrm{h}_{\mathrm{f}}=8 \mathrm{~mm}$ as well as $h_{i}=1.5 \mathrm{~mm}$ and $h_{f}=6 \mathrm{~mm}$ ) in order to elucidate their effect on filament thinning. Initial gap heights $h_{i}>1.5 \mathrm{~mm}$ are not feasible, due to the low surface tension of the investigated fluids. The liquid under test flows out of the gap and a correct filling is not possible. If the ratio $h_{f} / h_{i}$ is chosen too high, filaments break before the upper plate has reached its end position, e.g., for $h_{f}=6 \mathrm{~mm}$ and $h_{i}=0.5 \mathrm{~mm}$ uniform filaments could only be formed for the $100 \mathrm{mM} \mathrm{CPyCl} / \mathrm{NaSal}$ solutions with $\mathrm{R}=0.5$ and $\mathrm{R}=5$. Tilted CaBER experiments on $\mathrm{CPyCl} / \mathrm{NaSal} / \mathrm{NaCl}$ and $\mathrm{CTAB} / \mathrm{NaSal}$ [Sachsenheimer et al. (submitted)] have revealed that high axial normal stresses $\sigma_{\mathrm{zz}}$ occur during the initial period of thinning, and we suppose that filament rupture occurs during the step-strain period when $\sigma_{\mathrm{zz}}$ exceeds a critical value the filament can bear. This idea is supported by FiSER experiments on $\mathrm{CTAB} / \mathrm{NaSal}$ solutions, where a critical axial normal stress at filament rupture independent of elongation rate was found [Bhardwaj et al. (2007b)].

Choosing $\mathrm{h}_{\mathrm{i}}=1.5 \mathrm{~mm}$ and $\mathrm{h}_{\mathrm{f}}=6 \mathrm{~mm}$ enabled us to characterize the capillary thinning of WLM solutions in a broad range of surfactant concentrations and salt/surfactant ratios $\mathrm{R}$ covering both viscosity maxima and hence spanning several orders of magnitude with respect to shear viscosity. The influence of the strike time $t_{s}$ on the filament lifetime $t_{\text {fil }}$ was investigated for $\mathrm{CPyCl} / \mathrm{NaSal}$ and $\mathrm{CTAB} / \mathrm{NaSal}$ solutions covering both viscosity maxima, and $t_{\mathrm{s}}$ was varied between $t_{\mathrm{s}}=20 \mathrm{~ms}$ and $\mathrm{t}_{\mathrm{s}}=160 \mathrm{~ms}$. Longer strike times are not recommended because of a potential superposition of filament stretching and capillary thinning [Sachsenheimer et al. (submitted)]. However, no variations of the filament lifetime were found within experimental error in contrast to the observations of Miller et al. (2009) who reported a significant influence of $t_{\mathrm{s}}$ and $\mathrm{h}_{\mathrm{f}}$ on the filament lifetime but in good agreement with the results of Kim et al. (2010) who could not recover an influence of initial step-strain parameters on the elongational relaxation time.

\section{B. Characteristic filament shape and diameter decay}

In the following filament formation and subsequent capillary thinning will be discussed based on results obtained for $\mathrm{CPyCl} / \mathrm{NaSal}$ and $\mathrm{CTAB} / \mathrm{NaSal}$ solutions. Three characteristic types of filament shape and diameter evolution are observed for these WLM solutions. Typical pictures of fluid filaments at different stages of thinning are shown in Fig. 2.

Filaments made from the $\mathrm{CPyCl} / \mathrm{NaSal}$ solutions show a cylindrical region near the midpoint of the thread only in the final stage of thinning $\left(t>3 / 5 t_{\text {fil }}\right)$, whereas a curved filament shape is observed at the beginning of the thinning process. This shape evolution is typical for visco-elastic fluids, where the thinning process is initially controlled by viscous 


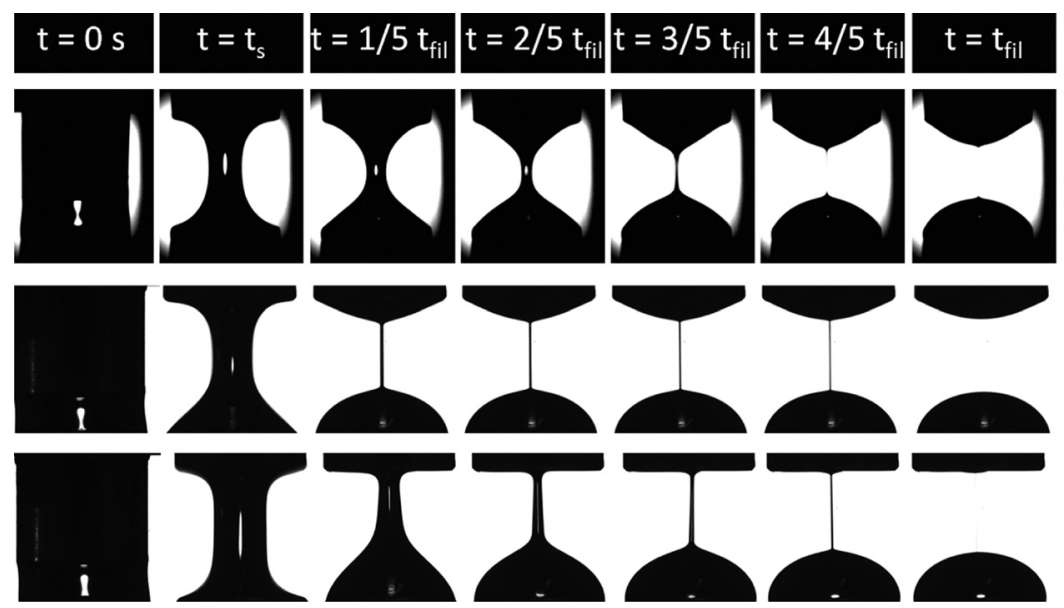

FIG. 2. Typical images of fluid filaments taken during CaBER experiments $\left(\mathrm{h}_{\mathrm{i}}=1.5 \mathrm{~mm}, \mathrm{~h}_{\mathrm{f}}=6 \mathrm{~mm}\right.$, $\mathrm{t}_{\mathrm{s}}=40 \mathrm{~ms}$ ) at different stages of capillary thinning relative to the filament lifetime $\mathrm{t}_{\mathrm{fil}}$ for $100 \mathrm{mM} \mathrm{CPyCl} / \mathrm{NaSal}$ with $\mathrm{R}=0.5$ (top), $25 \mathrm{mM} \mathrm{CTAB} / \mathrm{NaSal}$ with $\mathrm{R}=0.5$ (middle) and $25 \mathrm{mM} \mathrm{CTAB} / \mathrm{NaSal}$ with $\mathrm{R}=4.5$ (bottom).

and capillary forces until finally elasto-capillary thinning dominates [Clasen (2010); Sachsenheimer et al. (submitted)]. The Newtonian response also shows up in the linear decrease of the filament diameter during the early thinning period, whereas exponential filament diameter decay is observed in the final stage controlled by elasto-capillary thinning as shown in Fig. 3. Similar results were found for $\mathrm{CPyCl} / \mathrm{NaSal} / \mathrm{NaCl}$ solutions analyzing the axial force in the liquid thread [Sachsenheimer et al. (submitted)]. Finally, the fluid filament breaks and in certain cases this is preceded by a bead-on-a-string structure, but this phenomenon is not discussed in this paper. Filament lifetime for these $\mathrm{CPyCl} / \mathrm{NaSal}$ solutions varies between $\mathrm{t}_{\mathrm{fil}} \approx 0.2 \mathrm{~s}$ and $\mathrm{t}_{\mathrm{fil}} \approx 60 \mathrm{~s}$ depending on the salt/surfactant ratio $\mathrm{R}$.

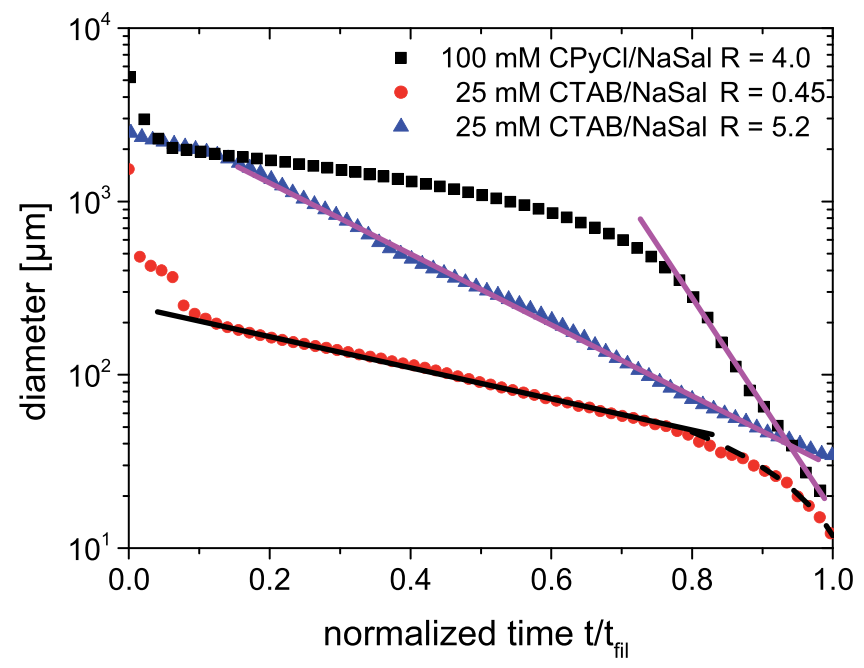

FIG. 3. Filament diameter as a function of normalized time $\mathrm{t} / \mathrm{t}_{\mathrm{fil}}$ determined at $\mathrm{T}=20^{\circ} \mathrm{C}$ for $100 \mathrm{mM} \mathrm{CPyCl} /$ $\mathrm{NaSal}$ with $\mathrm{R}=4.0\left(\eta_{0}=1.2 \mathrm{Pas}\right.$ and $\left.\mathrm{t}_{\mathrm{fil}}=0.8 \mathrm{~s}\right)$ as well as $25 \mathrm{mM} \mathrm{CTAB} / \mathrm{NaSal}$ with $\mathrm{R}=0.4\left(\eta_{0}=0.076 \mathrm{Pas}\right.$ and $\left.\mathrm{t}_{\mathrm{fil}}=107 \mathrm{~s}\right)$ and $\mathrm{R}=5.2\left(\eta_{0}=36.2\right.$ Pas and $\left.\mathrm{t}_{\mathrm{fil}}=70 \mathrm{~s}\right)$. Number of shown data points is reduced for sake of clarity. The solid lines represent the exponentially thinning region where the elongational relaxation time is determined. The dashed curve represents the late Newtonian thinning regime observed for $\mathrm{CTAB} / \mathrm{NaSal}$ at $\mathrm{R}=0.45$ and is a fit of equation 1 to the experimental data in the time range $0.8<\mathrm{t} / \mathrm{t}_{\mathrm{fil}}<1$. 
The investigated $\mathrm{CTAB} / \mathrm{NaSal}$ solutions show a different characteristic filament shape and diameter vs time curve at low $\left(\mathrm{R}<\mathrm{R}_{\max }\right)$ and high $\left(\mathrm{R}>\mathrm{R}_{\max }\right)$ salt/surfactant ratio.

At low R (Fig. 2, middle), the filaments of $\mathrm{CTAB} / \mathrm{NaSal}$ solutions exhibit a perfect cylindrical shape during the whole thinning process as expected for viscoelastic solutions. The diameter $D_{1}$ determined right after the upper plate has reached the end position $\left(\mathrm{t}=\mathrm{t}_{\mathrm{s}}\right)$ is significantly smaller than for $\mathrm{CPyCl} / \mathrm{NaSal}$ solutions or $\mathrm{CTAB} / \mathrm{NaSal}$ solutions with $\mathrm{R}>\mathrm{R}_{\max }$ due to the low viscosity of this solution. The corresponding diameter vs time curve (Fig. 3) shows an extended regime of exponential thinning diameter followed by a linear decay prior to breakup. In this $\mathrm{R}$ range, filament lifetimes vary between $\mathrm{t}_{\text {fil }} \approx 50 \mathrm{~s}$ and $\mathrm{t}_{\text {fil }} \approx 800 \mathrm{~s}$.

$\mathrm{CTAB} / \mathrm{NaSal}$ solutions with high $\mathrm{R}$ values exhibit an asymmetric filament in the early stage of thinning controlled by gravitational sagging (Bond number $\mathrm{Bo}=\rho \mathrm{gD}^{2} / \Gamma>1$ ). As the thinning proceeds further, a cylindrical filament shape with exponentially decreasing diameter until filament breakage is observed. Filament lifetimes vary between $\mathrm{t}_{\text {fil }} \approx 40 \mathrm{~s}$ and $\mathrm{t}_{\text {fil }} \approx 800 \mathrm{~s}$.

All three thinning periods (early Newtonian, visco-elastic and late Newtonian) observed here for WLM solutions can be covered using a finitely extensible nonlinear elastic (FENE) model [Entov and Hinch (1997)]. In addition, the occurrence of an early Newtonian thinning regime has been associated with the dimensionless elasto-capillary number Ec $=2 \lambda_{\mathrm{s}} \Gamma / \eta_{0} \mathrm{D}$ which is the dimensionless ratio of the elastic stress and capillary pressure within the filament [Anna and McKinley (2001); Clasen et al. (2006); Clasen (2010), Sachsenheimer et al. (submitted)]. Furthermore, the late Newtonian regime has been attributed to the finite extensibility parameter of polymer molecules or WLM structures [Entov and Hinch (1997); Rothstein (2003); Chellamuthu and Rothstein (2008)]. However, an exponentially decreasing diameter region allowing for an unambiguous determination of the elongational relaxation time $\lambda_{\mathrm{e}}$ is found for all WLM solutions investigated in this study.

\section{Filament thinning behavior of $\mathrm{CPyCl} / \mathrm{NaSal}$ and $\mathrm{CTAB} / \mathrm{NaSal}$ solutions}

In Fig. 4, filament lifetime $\mathrm{t}_{\text {fil }}$ is plotted as a function of the salt/surfactant ratio $\mathrm{R}$ for the $100 \mathrm{mM} \mathrm{CPyCl} / \mathrm{NaSal}$ and the $25 \mathrm{mM} \mathrm{CTAB} / \mathrm{NaSal}$ solutions. These surfactant concentrations are compared here because they yield similar $\eta_{0}$ and $\lambda_{\mathrm{s}}$ values for

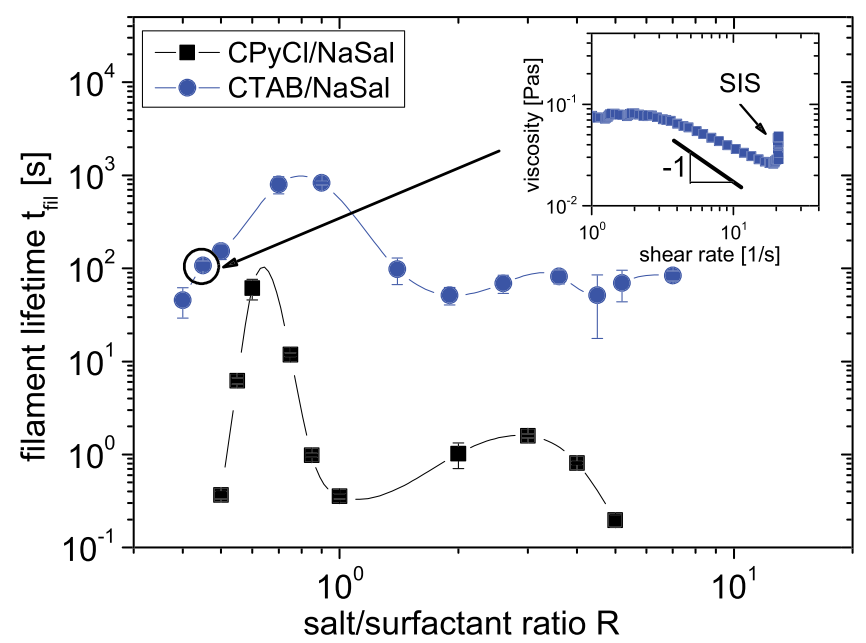

FIG. 4. Filament lifetime $t_{\text {fil }}$ as a function of salt/surfactant ratio $\mathrm{R}$ for $100 \mathrm{mM} \mathrm{CPyCl} / \mathrm{NaSal}$ and $25 \mathrm{mM}$ $\mathrm{CTAB} / \mathrm{NaSal}$ at $\mathrm{T}=20^{\circ} \mathrm{C}$. Lines are to guide the eye. 
$\mathrm{R}<\mathrm{R}_{\max }$. Here, we plot $\mathrm{t}_{\mathrm{fil}}$ which can be determined from $\mathrm{D}(\mathrm{t})$ in a straight forward manner. However, the elongational relaxation time $\lambda_{\mathrm{e}}$ obtained from the exponential diameter decay regime exhibits a similar dependency on $\mathrm{R}$ and reveals the same differences between the $\mathrm{CPyCl}$ and $\mathrm{CTAB}$ systems.

Significant differences between the $\mathrm{CTAB} / \mathrm{NaSal}$ and $\mathrm{CPyCl} / \mathrm{NaSal}$ system show up in the CaBER experiments, even at low $\mathrm{R}$ values, where the shear rheological properties $\eta_{0}$ and $\lambda_{\mathrm{s}}$ are nearly identical (see Fig. 1). In the whole salt concentration range, $\mathrm{t}_{\mathrm{fil}}$ or $\lambda_{\mathrm{e}}$ is (up to three orders of magnitude) higher for the $\mathrm{CTAB} / \mathrm{NaSal}$ system than for the $\mathrm{CPyCl} / \mathrm{NaSal}$ system. The maximum filament lifetime is $\mathrm{t}_{\mathrm{fil}}^{\max } \approx 1000 \mathrm{~s}$ and $\mathrm{t}_{\mathrm{fil}}^{\max } \approx 60 \mathrm{~s}$ for $\mathrm{CTAB} / \mathrm{NaSal}$ and $\mathrm{CPyCl} / \mathrm{NaSal}$, respectively. It should be kept in mind that the $\mathrm{CTAB}$ concentration at which such stable filaments occurs is only a fourth of the $\mathrm{CPyCl}$ concentration. The long filament lifetimes observed for $\mathrm{CTAB} / \mathrm{NaSal}$ solutions at low $\mathrm{R}$ values are most likely due to an EIS formation because the system $\mathrm{CTAB} / \mathrm{NaSal}$ is known to undergo structural changes during flow [Liu and Pine (1996); Ouchi et al. (2006b); Vasudevan et al. (2008); Lutz-Bueno et al. (2013)] in the concentration range in which our CaBER experiments indicate EIS. This structure formation effect is mostly investigated in shear flows [Liu and Pine (1996); Ouchi et al. (2006b); Vasudevan et al. (2008); Lutz-Bueno et al. (2013)], where the SIS shows up in a sudden increase of the steady shear viscosity $\eta$ at a critical shear rate $\dot{\gamma}_{c}$ (see inset in Fig. 4), critical shear stress or a critical total shear deformation. Generally, the occurrence of shear thickening in WLM solutions can also result from elastic instabilities [Britton and Callaghan (1999); Fardin et al. (2011); Fardin et al. (2012a); Fardin et al. (2012b); Fardin and Lerouge (2012); Beaumont et al. (2013); Perge et al. (2014)]. But in these cases, shear banding is observed (elucidated by a slope of -1 in the steady viscosity function) prior to shear thickening. Furthermore, elastic instabilities have been observed for $\mathrm{CPyCl} / \mathrm{NaSal} / \mathrm{NaCl}$ $\left(\mathrm{c}_{\mathrm{s}}=238 \mathrm{mM}\right)$ and $\mathrm{CTAB} / \mathrm{NaNO}_{3}\left(\mathrm{c}_{\mathrm{s}}=30 \mathrm{mM}\right)$ [Britton and Callaghan (1999); Fardin et al. (2011); Fardin et al. (2012a); Fardin et al. (2012b); Fardin and Lerouge (2012)] but neither SIS has been reported in the literature, nor did we find any indication of EIS. Interestingly, capillary thinning behavior of solutions showing shear banding (fast braking limit, $R>R_{\max }$ ) is controlled by linear viscoelastic shear properties (see Sec. III D). So it seems flow instabilities do not occur in this flow kinematics. The phenomenon of long stable filaments will be discussed in more detail below.

\section{Fast-breaking limit}

Shear and elongational relaxation times are compared in Fig. 5 showing the relaxation time ratio $\lambda_{\mathrm{e}} / \lambda_{\mathrm{s}}$ as a function of salt/surfactant ratio $\mathrm{R}$ for the $100 \mathrm{mM} \mathrm{CPyCl} / \mathrm{NaSal}$ and the $25 \mathrm{mM} \mathrm{CTAB} / \mathrm{NaSal}$ systems.

For high R, i.e., in the fast-breaking limit, linear viscoelastic shear relaxation is described by a single-mode Maxwell model in a wide frequency range (see, e.g., inset in Fig. 6). The relaxation time ratio $\lambda_{\mathrm{e}} / \lambda_{\mathrm{s}}$ is fairly independent of $\mathrm{R}$. The difference between $\lambda_{\mathrm{e}} / \lambda_{\mathrm{s}}=0.4 \pm 0.2$ for $\mathrm{CPyCl} / \mathrm{NaSal}$ solutions and $\lambda_{\mathrm{e}} / \lambda_{\mathrm{s}}=0.9 \pm 0.4$ for CTAB/NaSal solutions may be explained by differences in micellar flexibility. More importantly, finding a constant relaxation time ratio of $\lambda_{\mathrm{e}} / \lambda_{\mathrm{s}} \approx 1$ indicates that the capillary thinning behavior is characterized by linear material properties which can be obtained from simple oscillatory shear experiments [see also Sachsenheimer et al. (submitted)].

This hypothesis is further supported by the universal scaling of the reduced filament lifetime $\mathrm{t}_{\text {fil }} / \mathrm{G}_{0}$ with the equilibrium micellar breakage time $\lambda_{\text {br }}$ shown in Fig. 6 summarizing data for six different WLM systems at different surfactant concentrations, salt/surfactant ratios, and temperatures. The linear viscoelastic fluid properties $G_{0}$ and $\lambda_{\text {br }}$ are 


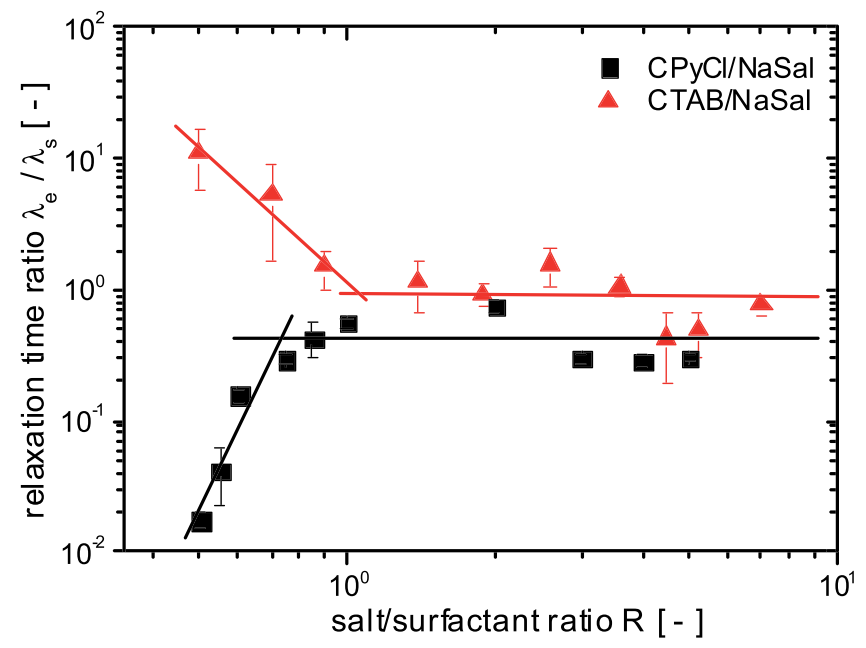

FIG. 5. Relaxation time ratio $\lambda_{\mathrm{e}} / \lambda_{\mathrm{s}}$ as a function of salt/surfactant ratio $\mathrm{R}$ for $100 \mathrm{mM} \mathrm{CPyCl} / \mathrm{NaSal}$ and $25 \mathrm{mM}$ $\mathrm{CTAB} / \mathrm{NaSal}$ at $\mathrm{T}=20^{\circ} \mathrm{C}$.

determined from SAOS experiments (at the same measurement temperature) as illustrated in the inset of Fig. 6 where the storage and loss moduli $G^{\prime}$ and $G^{\prime \prime}$ are plotted against the angular frequency $\omega$. The breakage time is defined as the reciprocal angular frequency at which the loss modulus shows a minimum value, $\lambda_{\mathrm{br}}=1 / \omega\left(\mathrm{G}_{\mathrm{min}}^{\prime \prime}\right)$, [Fischer and Rehage (1997); Yesilata et al. (2006)] and the plateau modulus $\mathrm{G}_{0}$ is determined from $\mathrm{G}^{\prime}$ at the same angular frequency, $\mathrm{G}_{0}=\mathrm{G}^{\prime}\left(\omega\left(\mathrm{G}_{\min }^{\prime \prime}\right)\right)$. The ratio of filament lifetime and plateau modulus clearly depends on the breakage time and all data points collapse to one master curve according to $t_{\mathrm{fil}} / \mathrm{G}_{0} \propto \lambda_{\mathrm{br}}^{3 / 2}$ irrespective of the type of surfactant, the behavior of the salt (strongly binding or not), and the measurement temperature. This

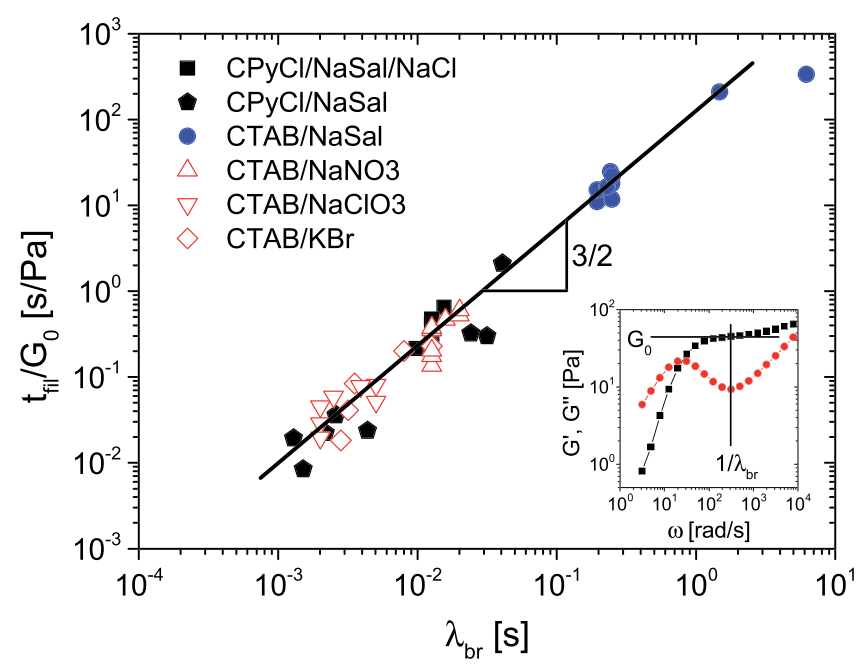

FIG. 6. Ratio of filament lifetime and plateau modulus as a function of the breakage time of the micelles for different WLM solutions as mentioned in the diagram. Different data points represented by the same symbol refer to different $\mathrm{R}$ values or in case of $\mathrm{CPyCl} / \mathrm{NaSal} / \mathrm{NaCl}$ solutions to different surfactant concentrations. The solid line represents a power law fit to the experimental data with an exponent of $3 / 2$. The inset shows the storage and loss moduli for a $25 \mathrm{mM} \mathrm{CPyCl} / \mathrm{NaSal}$ solution $(\mathrm{R}=0.8)$ as a function of the angular frequency illustrating the determination of $\mathrm{G}_{0}$ and $\lambda_{\mathrm{br}}$. Measurement temperatures are given in Table $\mathrm{I}$. 
scaling law also holds for solutions with $\lambda_{\mathrm{e}} / \lambda_{\mathrm{s}}<1$ as long as a minimum in $\mathrm{G}^{\prime \prime}$ is still present. A similar scaling is found when $\mathrm{t}_{\mathrm{fil}}$ is replaced by $\lambda_{\mathrm{e}}$. The correlation can also be given in terms of dimensionless numbers dividing the times by $\sqrt{\rho V / \Gamma}$, where $\rho$ is the density and $\mathrm{V}$ is the sample volume as well as dividing the modulus by the initial Laplace pressure $2 \Gamma / \mathrm{D}_{0}$.

These findings indicate that no flow-induced structural change occurs in this salt/surfactant regime and the breaking rate of the micelles does not change during elongational flow in a CaBER experiment.

\section{E. Low salt regime}

Striking differences are observed between $\mathrm{CPyCl} / \mathrm{NaSal}$ and $\mathrm{CTAB} / \mathrm{NaSal}$ solutions in the low salt limit. For the $\mathrm{CPyCl} / \mathrm{NaSal}$ system, $\lambda_{\mathrm{e}} / \lambda_{\mathrm{s}}$ starts at values much lower than one $\left(\lambda_{\mathrm{e}} / \lambda_{\mathrm{s}} \approx 0.02\right)$ and increases with increasing salt concentration until the plateau is reached at high $\mathrm{R}$. Relaxation time ratios $\lambda_{\mathrm{e}} / \lambda_{\mathrm{s}} \ll 1$ found for low $\mathrm{R}$ values might be taken as evidence for a flow-induced decrease of the mean length of micelles, but such low $\lambda_{\mathrm{e}} / \lambda_{\mathrm{s}}$ values are also observed for solutions of covalently bound polymers in the entangled state and $\lambda_{\mathrm{e}} / \lambda_{\mathrm{s}}$ values as low as 0.01 are reported in the literature [Liang and Mackley (1994); Oliveira et al. (2006); Clasen (2010); Arnolds et al. (2010); Sachsenheimer et al. (submitted)]. Therefore, it is not very surprising that WLM solutions where the reptation is the dominant stress relaxation mechanism, show $\lambda_{\mathrm{e}} / \lambda_{\mathrm{s}} \ll 1$. Similar results are also obtained for $\mathrm{CTAB} / \mathrm{NaNO}_{3}, \mathrm{CTAB} / \mathrm{NaClO}_{3}$, and $\mathrm{CTAB} / \mathrm{KBr}$ solutions at low $\mathrm{R}$ values investigated in this study. Nevertheless, structural analysis under elongational flow, e.g., neutron scatting, would be useful for clarifying the origin of these findings unambiguously, but this is beyond the scope of this paper and will be addressed in a subsequent study.

In contrast, the relaxation time ratio of the $\mathrm{CTAB} / \mathrm{NaSal}$ solutions at low salt concentrations starts at approximately $\lambda_{\mathrm{e}} / \lambda_{\mathrm{s}}=10$ and decreases with increasing salt/surfactant ratio $\mathrm{R}$ reaching a plateau for $\mathrm{R} \approx 1>\mathrm{R}_{\max }$. Such high relaxation time ratios have never been reported in the literature (to the best of our knowledge) and we hypothesize an elongationinduced structural change stabilizing the filaments as already mentioned above. In this case, $\lambda_{\mathrm{e}}$ corresponds to the characteristic thinning time scale of the flow-induced structure and $\lambda_{\mathrm{s}}$ corresponds to the characteristic relaxation time scale of the equilibrium structure of the WLM solutions at rest. This topic will be discussed in more detail below.

\section{F. Distinguishing between linear and branched micelles}

Figure 7 shows the filament lifetime $t_{\text {fil }}$ as a function of zero-shear viscosity $\eta_{0}$ for different WLM solutions investigated in this study. $\mathrm{CPyCl} / \mathrm{NaSal}$ solutions [Fig. 7(a)] with similar zero-shear viscosity exhibit a significantly lower filament lifetime in the case of linear micelles $\left(R<R_{\max }\right)$ than in the case of branched ones $\left(R>R_{\max }\right)$. Furthermore, the filament lifetime depends more strongly on zero-shear viscosity in the linear regime $\left(\mathrm{t}_{\text {fil }} \propto \eta_{0}^{1.3}\right)$ than in the branched regime $\left(\mathrm{t}_{\text {fil }} \propto \eta_{0}^{0.9}\right)$. For $\mathrm{CPyCl} / \mathrm{NaSal}$ solutions, the change of the micellar morphology from a linear to branched structure at $\mathrm{R}_{\max }$ is confirmed by rheological measurements [Oelschlaeger et al. (2009)] and cryo-TEM studies [Abezgauz and Danino (2007)]. Similar results are obtained for the $\mathrm{CTAB} / \mathrm{NaClO}_{3}$ system, when solutions with $\mathrm{R}<\mathrm{R}_{\max }$ and $\mathrm{R}>\mathrm{R}_{\max }$ are compared [Fig. 7(c)]. For $\mathrm{CTAB} / \mathrm{NaNO}_{3}$ solutions [Fig. 7(b)], the scaling exponent $\mathrm{t}_{\mathrm{fil}} \propto \eta_{0}^{\alpha}$ decreases from $\alpha=1.3$ to $\alpha=0.9$ at a critical salt/surfactant value $\mathrm{R}=5.7$ indicating a linear to branched micelles transition. This hypothesis is further supported by cryo-TEM images [Helgeson et al. (2010)] and by Oelschlaeger et al. [Oelschlaeger et al. (2010)] who observed a characteristic increase of the plateau modulus $\mathrm{G}_{0}$ at $\mathrm{R} \approx 5.0$ for a $350 \mathrm{mM} \mathrm{CTAB} / \mathrm{NaNO}_{3}$ solution. 

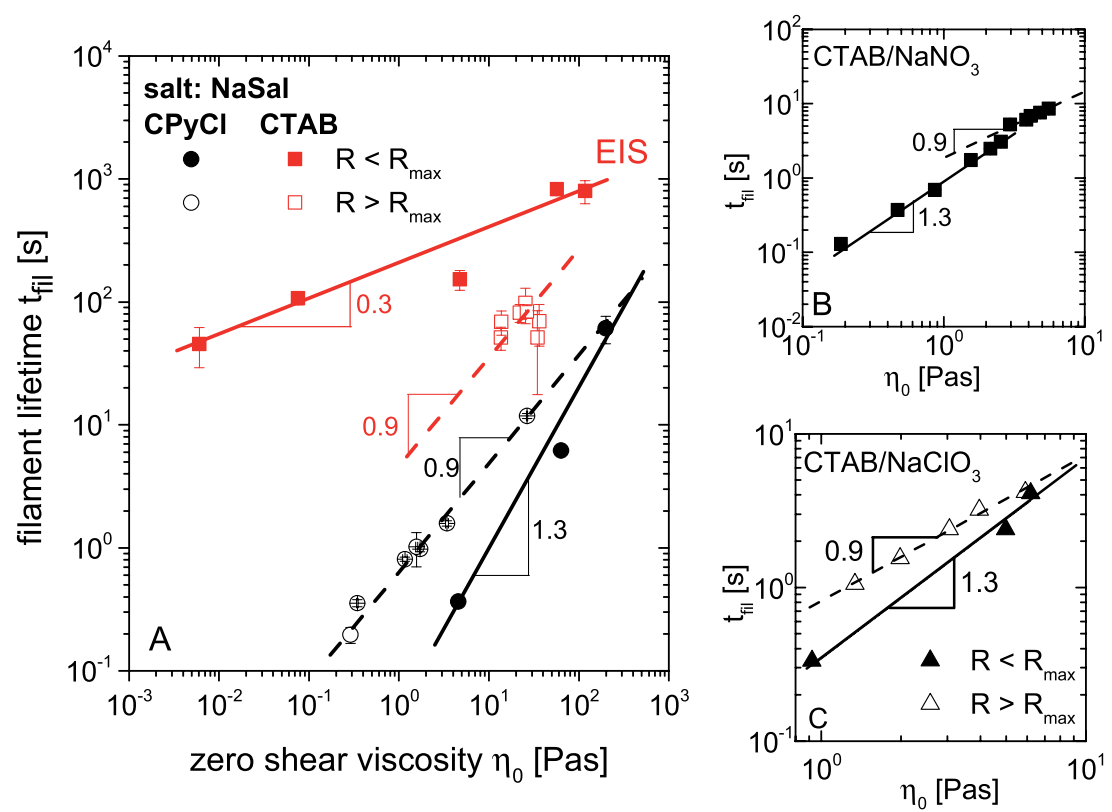

FIG. 7. Filament lifetime $\mathrm{t}_{\mathrm{fil}}$ as a function of zero-shear viscosity $\eta_{0}$ for $100 \mathrm{mM} \mathrm{CPyCl} / \mathrm{NaSal}, 25 \mathrm{mM} \mathrm{CTAB} /$ NaSal (both left, measurement temperature $\mathrm{T}=20^{\circ} \mathrm{C}$ ), $75 \mathrm{mM} \mathrm{CTAB} / \mathrm{NaNO}_{3}$ (top right, $\mathrm{T}=25^{\circ} \mathrm{C}$ ), and $150 \mathrm{mM} \mathrm{CTAB} / \mathrm{NaClO}_{3}$ (bottom right $\mathrm{T}=30^{\circ} \mathrm{C}$ ) at $\mathrm{R}<\mathrm{R}_{\max }$ (filled symbols) and $\mathrm{R}>\mathrm{R}_{\max }$ (open symbols).

For the branched CTAB/NaSal solutions with $\mathrm{c}_{\mathrm{s}}=25 \mathrm{mM}$ and $\mathrm{R}>\mathrm{R}_{\max }$ the filament lifetime $t_{\text {fil }}$ hardly changes with the zero-shear viscosity $\eta_{0}$, both quantities depend only weakly on R. This hinders an accurate determination of a scaling exponent but the variation of lifetime with $\eta_{0}$ seems to be consistent with the scaling law $\mathrm{t}_{\mathrm{fil}} \propto \eta_{0}^{0.9}$ found for the other systems. However, filament lifetime is much larger for solutions with $\mathrm{R}<\mathrm{R}_{\max }$ than for solutions with $\mathrm{R}>\mathrm{R}_{\max }$ and varies only weakly with zero-shear viscosity $\left(\mathrm{t}_{\mathrm{fil}} \propto \eta_{0}^{0.3}\right)$. This is in contrast to the findings for the other systems and is taken as further evidence for EIS occurring in CTAB/NaSal solutions with $\mathrm{R}<\mathrm{R}_{\max }$.

EIS formation also may have occurred in another system investigated by Chellamuthu and Rothstein [Chellamuthu and Rothstein (2008)]. They focused on solutions of sodium oleate $(\mathrm{NaOA})$ and octyl trimethyl ammonium bromide $\left(\mathrm{C}_{8} \mathrm{TAB}\right)$ at a fixed mass ratio of $7: 3$ and different total surfactant concentrations $\mathrm{c}_{\mathrm{s}}$. For solutions at $\mathrm{c}_{\mathrm{s}}<c_{\mathrm{s}, \max }=4 \mathrm{wt}$. $\%$ long filament lifetimes and high maximum Trouton ratios are reported. For $\mathrm{c}_{\mathrm{s}}>c_{\mathrm{s}, \max }$, where micelles show a branched structure [Ziserman et al. (2004)] a rapid decrease of the maximum Trouton ratio with increasing $\mathrm{c}_{\mathrm{s}}$ is found. This observation was taken as evidence for extremely efficient stress relief mechanisms due to sliding of branching points and ghostlike crossing.

However, the shape of the diameter vs time curve for $\mathrm{NaOA} / \mathrm{C}_{8} \mathrm{TAB}$ solutions at $\mathrm{c}_{\mathrm{s}}<$ $\mathrm{c}_{\mathrm{s}, \max }$ is very similar to that obtained for CTAB/NaSal solutions at $\mathrm{R}<\mathrm{R}_{\max }$ (EIS regime). Corresponding steady shear experiments show a sudden increase of viscosity or normal stress difference at a critical shear rate (e.g., $\dot{\gamma}_{c}=94 \pm 7 \mathrm{~s}^{-1}$ for $\mathrm{c}_{\mathrm{s}}=2 \mathrm{wt}$. \%) supposed to indicate a structure build-up in shear. The drastic change in the elongational behavior occurring around $c_{s, \max }$ reported by Chellamuthu and Rothstein seems to be more likely due to a flow-induced structure formation than due to a transition between linear and branched micelles as hypothesized in their paper. Furthermore, it should be noted that the measured filament lifetimes of $\mathrm{NaOA} / \mathrm{C}_{8} \mathrm{TAB}$ solutions at $\mathrm{c}_{\mathrm{s}} \geq \mathrm{c}_{\mathrm{s}, \max }$ are lower than the 


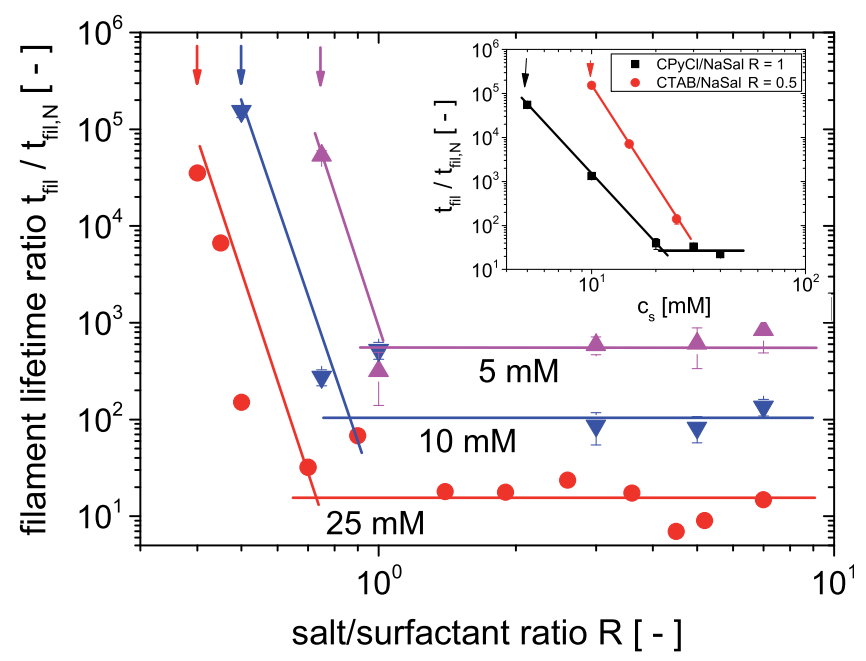

FIG. 8. Filament lifetime ratio $t_{\text {fil }} / t_{\text {fil, N }}$ as a function of the salt surfactant ratio $\mathrm{R}$ for $\mathrm{CTAB} / \mathrm{NaSal}$ solutions with surfactant concentrations of $5 \mathrm{mM}, 10 \mathrm{mM}$, and $25 \mathrm{mM}$ at $\mathrm{T}=20^{\circ} \mathrm{C}$. The inset shows $\mathrm{t}_{\mathrm{fil}} / \mathrm{t}_{\mathrm{fil}, \mathrm{N}}$ as a function of the surfactant concentration for $\mathrm{CPyCl} / \mathrm{NaSal}$ solutions with $\mathrm{R}=1$ and $\mathrm{CTAB} / \mathrm{NaSal}$ solutions with $\mathrm{R}=0.5$. The arrows indicate the critical $\mathrm{R}$ value at a given concentration or a critical surfactant concentration at a given $\mathrm{R}$ value, respectively, above which EIS are observed. Lines are to guide the eye.

theoretical values calculated from the zero-shear viscosity assuming Newtonian flow behavior. This may indicate a flow-induced decrease of the mean length of the micelles.

Finally, distinguishing between linear and branched micelles based on CaBER measurements seems to be possible but is not unambiguous. In general, the micellar structure can change during flow (e.g., EIS formation as observed for CTAB/NaSal solutions for $\mathrm{R}<$ $\mathrm{R}_{\max }$ or breakage of micelles most likely to occur in $\mathrm{NaOA} / \mathrm{C}_{8} \mathrm{TAB}$ solutions for $\left.\mathrm{c}_{\mathrm{s}}>\mathrm{c}_{\mathrm{s}, \max }\right)$.

\section{G. Flow-induced structure build-up}

As discussed above, the phenomenon of EIS formation is suggested by the high $\lambda_{\mathrm{e}} / \lambda_{\mathrm{s}}$ ratios observed for $25 \mathrm{mM} \mathrm{CTAB} / \mathrm{NaSal}$ solutions at low salt/surfactant ratios $\mathrm{R}$. In order to shed more light on EIS, we have investigated $\mathrm{CTAB} / \mathrm{NaSal}$ and $\mathrm{CPyCl} / \mathrm{NaSal}$ solutions with lower surfactant concentration again covering a broad $\mathrm{R}$ range. In Fig. 8, we compare the filament lifetime $\mathrm{t}_{\text {fil }}$ obtained in our CaBER experiment to the theoretical filament lifetime $t_{\text {fil, } N}$ calculated from the zero-shear viscosity of the solutions assuming Newtonian flow behavior during capillary thinning. Introducing this value is necessary because shear relaxation time could not be determined for the low viscosity WLM solutions with low surfactant concentration, and therefore, the relaxation time ratio $\lambda_{\mathrm{e}} / \lambda_{\mathrm{s}}$ could not be calculated. The filament lifetime ratio $t_{\text {fil }} / t_{\mathrm{fil}, \mathrm{N}}$ is plotted as a function of $\mathrm{R}$ for CTAB/NaSal solutions with 5,10 , and $25 \mathrm{mM}$ surfactant concentration as well as for $\mathrm{CPyCl} / \mathrm{NaSal}$ with $\mathrm{R}=1$ and $\mathrm{CTAB} / \mathrm{NaSal}$ with $\mathrm{R}=0.5$ as a function of surfactant concentration $\mathrm{c}_{\mathrm{s}}$.

For all surfactant systems, the filament lifetime ratio starts at high values of $\mathrm{t}_{\text {fil }} / \mathrm{t}_{\mathrm{fil}, \mathrm{N}} \approx 10^{5}$ but strongly decreases with increasing salt/surfactant ratio $\mathrm{R}$ and levels off at a constant value for $\mathrm{R}>\mathrm{R}_{\max }$. Similar results are obtained for $\mathrm{CPyCl} / \mathrm{NaSal}$ solutions with $\mathrm{R}=1$ but different surfactant concentrations as illustrated in the inset of Fig. 8. For the $25 \mathrm{mM} \mathrm{CTAB} / \mathrm{NaSal}$ solution, this limiting $\mathrm{t}_{\mathrm{fil}} / \mathrm{t}_{\mathrm{fil}, \mathrm{N}}$ ratio is around ten and corresponds to $\lambda_{\mathrm{e}} / \lambda_{\mathrm{s}} \approx 1$ (see Fig. 5). As already discussed above, filament thinning in this case is controlled by the viscoelasticity of the entangled WLM network present at 


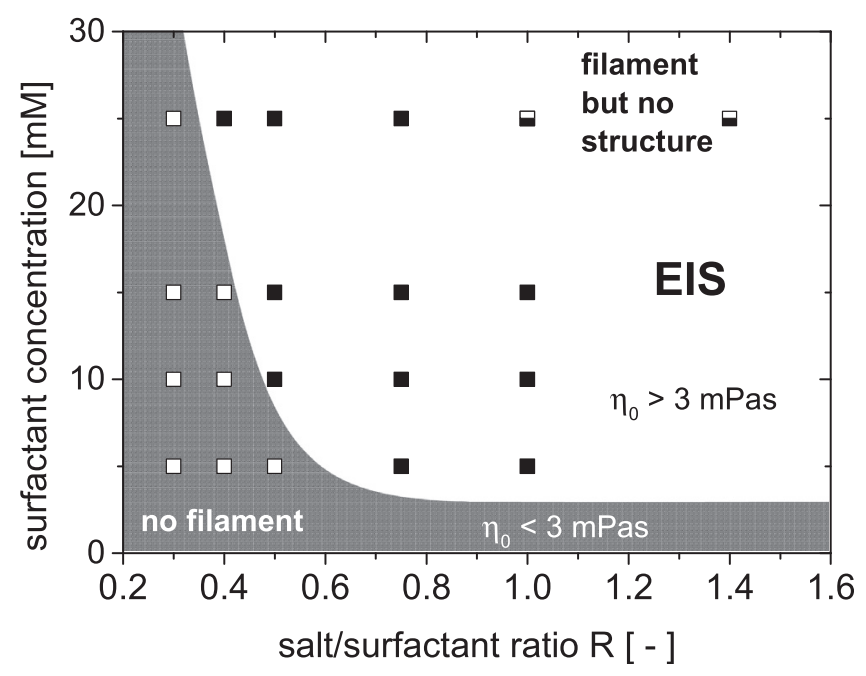

FIG. 9. Illustration of filament creation in CaBER experiments depending on the salt/surfactant ratio $\mathrm{R}$ and the surfactant concentration for $\mathrm{CTAB} / \mathrm{NaSal}$ solutions at $\mathrm{T}=20^{\circ} \mathrm{C}$. The dark gray area represents solutions where no filaments are created corresponding to zero-shear viscosities $\eta_{0}<3 \mathrm{mPas}$. The light gray area (half filled symbols) represents solutions where filaments are created but filament lifetime is controlled by the equilibrium viscoelasticity of the solutions and not by EIS formation. Filled symbols indicate solutions where EIS is found.

rest. In all other cases, filament lifetime ratios $t_{\text {fil }} / t_{\text {fill, }}$ between $10^{2}$ and $10^{5}$ are found indicating structure formation due to the elongational deformation during capillary thinning. This hypothesis is supported by the fact that all these solutions also show shear thickening and are prone to SIS formation.

It should be noted that performing multiple CaBER experiments on one and the same sample did not result in systematic variations in the filament lifetime confirming that the flow-induced structure formation is reversible. For a sake of clarity, we also want to note

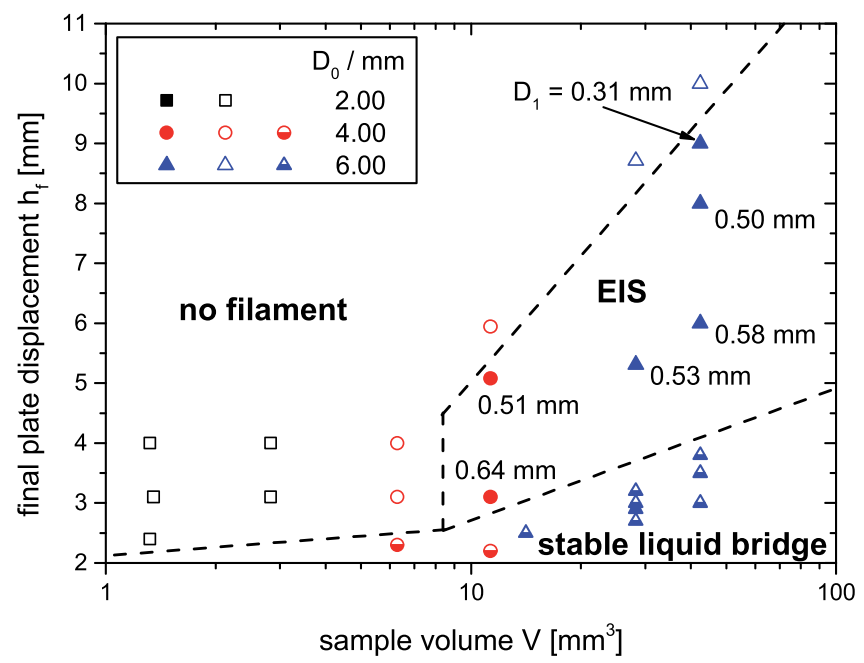

FIG. 10. Influence of final plate displacement $h_{f}$ and sample volume $V$ on filament creation for a $10 \mathrm{mM}$ $\mathrm{CTAB} / \mathrm{NaSal}$ solution with $\mathrm{R}=0.5$ for three different plate diameters $\mathrm{D}_{0}$ at $\mathrm{T}=20^{\circ} \mathrm{C}$. The $\mathrm{s}$ ample volume $\mathrm{V}$ is set by the plate diameter $\mathrm{D}_{0}$ and the plate displacement $\mathrm{h}_{\mathrm{i}}$ and thus characterizes the initial configuration of the CaBER experiment. 
that the solutions investigated by Okawara and Takahashi [Okawara et al. (2008); Okawara et al. (2009); Takahashi and Sakata (2011)] do not show EIS in CaBER.

However, finding structure formation in shear experiments does not automatically imply a corresponding effect during capillary thinning. Figure 9 illustrates the occurrence of EIS during capillary thinning of $\mathrm{CTAB} / \mathrm{NaSal}$ solutions exemplarily. For low salt/surfactant ratios $\mathrm{R}$, no filaments could be created in CaBER experiments indicating that no structural change occurs during the stretching process. Furthermore, no structure formation is observed for high surfactant concentrations $c_{\mathrm{s}}$ at high $\mathrm{R}$ values. In this case, the filament lifetime is only controlled by the viscoelasticity of the WLM solutions as already discussed above. It should be noted that for all solutions in the "no filament" and "EIS" region in Fig. 9, a structure formation has been found in shear experiments. The critical salt/surfactant ratio $R_{\text {crit }}$ at which EIS is observed (indicated by slowly thinning filaments), decreases with increasing surfactant concentration, and corresponds to a critical zero-shear viscosity of about $3 \mathrm{mPas}$. If the viscosity of the WLM solution is too low, the initial liquid bridge breaks during the initial step-strain deformation. This minimum viscosity criterion also holds if the surfactant concentration is too low, irrespective of R. Nevertheless, these solutions show shear thickening. This discrepancy may be rationalized assuming that a minimum energy input is needed for structure formation. While this energy input cannot take place during the fast step-strain deformation in a CaBER experiment it may be maintained in large deformation shear experiments. Finally, similar results have been obtained for $\mathrm{CPyCl} / \mathrm{NaSal}$ solutions but a slightly lower critical zero-shear viscosity of $2.2 \mathrm{mPas}$ is found in this case.

The influence of the final plate displacement $h_{f}$ and the sample volume $V$ on structure formation in a CaBER experiment is illustrated exemplarily in Fig. 10 for a $10 \mathrm{mM}$ $\mathrm{CTAB} / \mathrm{NaSal}$ solution with $\mathrm{R}=0.5$. Generally, stable liquid bridges are observed for low final plate displacements. The minimum $\mathrm{h}_{\mathrm{f}}$ needed for destabilization of the liquid bridge (followed by a thinning process) depends on surface tension and density of the solution but not on its viscosity or elasticity. Neglecting slight differences in solution density, critical $h_{f}$ values are independent of sample composition. However, if the final height $h_{f}$ is sufficiently large two cases of filament breakup are observed. For low sample volume V (corresponding to low initial gap height $h_{i}$ and small plate diameter $D_{0}$ ) the liquid bridge breaks during the initial step strain and no filament is created independent of the final plate separations $h_{f}$. This indicates that the thinning behavior is mainly controlled by the low zero-shear viscosity and no structure build-up takes place. Increasing V but holding the final displacement $h_{f}$ constant results in a dramatic increase of the filament lifetime indicating a structure build-up (EIS). Furthermore, for given initial sample volume (e.g., $\mathrm{V}=42 \mathrm{~mm}^{3}$, corresponding to $\mathrm{D}_{0}=6 \mathrm{~mm}$ and $\mathrm{h}_{\mathrm{i}}=1.5 \mathrm{~mm}$ ), the EIS phenomenon disappears if a critical $h_{f, c}$ value is exceeded. However, $h_{f, c}$ increases with increasing surfactant concentration, i.e., increasing solution viscosity, and the no filament region in the $\mathrm{h}_{\mathrm{f}}-\mathrm{V}$-plane disappears, e.g., for a $25 \mathrm{mM}$ CTAB/NaSal solution with $\mathrm{R}=0.5$.

The final displacement $h_{f}$, the sample volume $V$, and the zero-shear viscosity $\eta_{0}$ of the surfactant solution determine the filament diameter $\mathrm{D}_{1}$ measured right after the upper plate has reached the end position at $\mathrm{t}=\mathrm{t}_{\mathrm{s}}$. This quantity increases with increasing sample viscosity [see, for example, data in Clasen (2010)] and increasing V but decreases with increasing $h_{f}$. Our experimental results suggest that a minimum diameter $D_{1, \text { crit }}$ is needed for structure build-up of surfactant solutions in CaBER experiments. Values of $\mathrm{D}_{1, \text { crit }} \approx 0.3 \mathrm{~mm}$ are observed for a $10 \mathrm{mM} \mathrm{CTAB} / \mathrm{NaSal}$ solution with $\mathrm{R}=0.5$ (Fig. 10) but $D_{1 \text {,crit }}$ decreases slightly with increasing concentration $\left(D_{1, \text { crit }} \approx 0.26 \mathrm{~mm}\right.$ for $15 \mathrm{mM}$ $\mathrm{CTAB} / \mathrm{NaSal}, \mathrm{R}=0.5$ ). This finding is supported by shear experiments using parallel plate geometry [Herle et al. 2005], where the increase of viscosity due to a structure build-up is less pronounced if the gap width is decreased. 


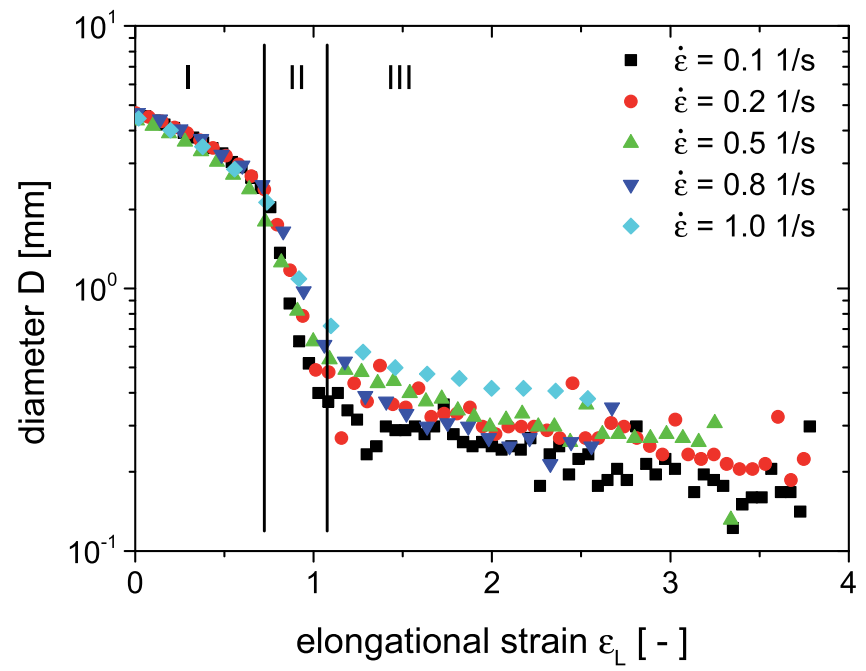

FIG. 11. Diameter as a function of total elongational strain $\varepsilon_{\mathrm{L}}$ determined in FiSER experiments with an initial plate displacement $\mathrm{L}_{0}=0.75 \mathrm{~mm}$ for a CTAB/NaSal solution with $\mathrm{c}_{\mathrm{s}}=10 \mathrm{mM}$ and $\mathrm{R}=0.75$ at $T=25 \pm 3{ }^{\circ} \mathrm{C}$.

Further insight into the EIS phenomenon is provided by FiSER experiments. In these experiments, the fluid drop is placed between two plates and the plates are separated at an exponentially increasing speed in order to maintain a constant elongation rate $\dot{\varepsilon}$. $\mathrm{CTAB} / \mathrm{NaSal}$ solutions with surfactant concentrations between $5 \mathrm{mM}$ and $20 \mathrm{mM}$ and $\mathrm{R}$ values between 0.7 and 1 have been investigated at nominal elongation rates between $0.1 \mathrm{~s}^{-1}$ and $1 \mathrm{~s}^{-1}$. Characteristic results for a $\mathrm{c}_{\mathrm{s}}=10 \mathrm{mM}$ and $\mathrm{R}=0.75$ are shown in Fig. 11 displaying the filament diameter $\mathrm{D}$ as a function of total strain $\varepsilon_{\mathrm{L}}(\mathrm{t})=\ln \left(\mathrm{L}(\mathrm{t}) / \mathrm{L}_{0}\right)$ for different strain rates.

The $\mathrm{D}\left(\varepsilon_{\mathrm{L}}\right)$ curves can be split into three parts. In the first period $\mathrm{D}$ decreases from its initial value $\mathrm{D}_{0} \approx 5 \mathrm{~mm}$ to $\mathrm{D}_{0} \approx 2.2 \mathrm{~mm}$ corresponding to the stretching of the liquid filament which still forms a stable bridge. The second stage is characterized by a rapid filament thinning. Finally, regime III is reached at a critical nominal strain $\varepsilon_{\mathrm{L}, \mathrm{c}}=1.1 \pm 0.1$.
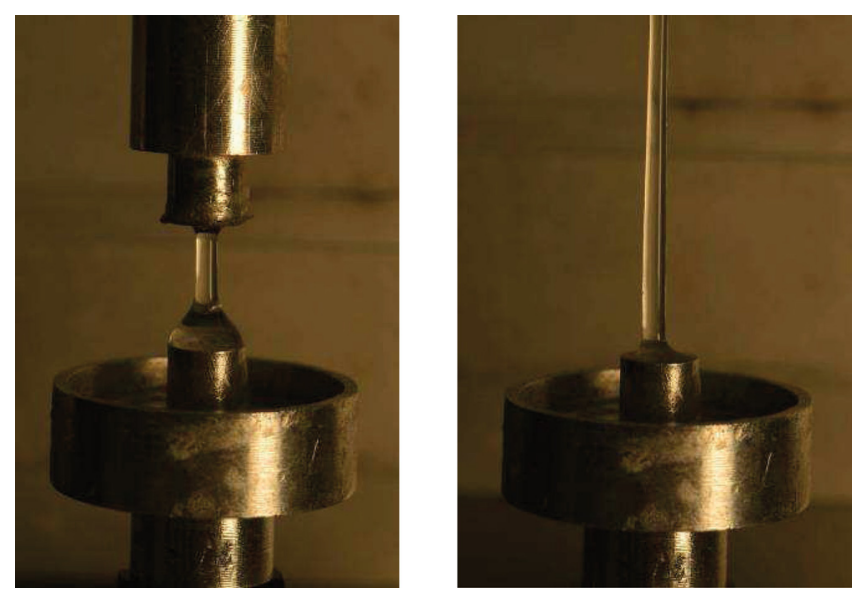

FIG. 12. Snapshots of a stretched liquid filament consisting of a $10 \mathrm{mM} C \mathrm{CAB} / \mathrm{NaSal}$ solution with $\mathrm{R}=1$ captured at the beginning and near the end of the third region in filament stretching performed using a FiSER apparatus at a constant elongational rate $\dot{\varepsilon}_{\mathrm{L}}=0.4$. 
In this regime, the slope of the $\mathrm{D}\left(\varepsilon_{\mathrm{L}}\right)$-curves dramatically decreases and this is attributed to the EIS build-up. In these FiSER experiments, structure formation always occurs at $\varepsilon_{\mathrm{L}, \mathrm{c}} \approx 1$ for all surfactant concentrations and $\mathrm{R}$ values investigated here irrespective of the applied nominal strain rate.

Figure 12 shows two snapshots of a FiSER experiment performed at a constant elongation rate of $\dot{\varepsilon}_{\mathrm{L}}=0.4$ for a $10 \mathrm{mM} \mathrm{CTAB} / \mathrm{NaSal}$ solution with $\mathrm{R}=1$. At the beginning (Fig. 12, left), a liquid reservoir is clearly visible at the lower plate. Further stretching yields only a slight decrease in the diameter but liquid is pulled out of the reservoir creating the new filament. This reveals the high stability of the filament and further supports the flow-induced structure build-up. Finally, the filament breaks at a finite diameter but not necessarily in the middle of the filament demonstrating the sensitivity of the structure to huge deformations presumably due to local fluctuations of structural strength.

\section{CONCLUSIONS}

We have investigated the capillary thinning of six different WLMs systems $(\mathrm{CPyCl} /$ $\mathrm{NaSal}, \mathrm{CPyCl} / \mathrm{NaSal} / \mathrm{NaCl}, \mathrm{CTAB} / \mathrm{NaSal}, \mathrm{CTAB} / \mathrm{KBr}, \mathrm{CTAB} / \mathrm{NaNO}_{3}$, and $\mathrm{CTAB} / \mathrm{NaClO}_{3}$ ) covering a wide range of surfactant concentrations $\mathrm{c}_{\mathrm{s}}$ and salt/surfactant ratios $\mathrm{R}$.

Figure 13 schematically summarizes the main results of our investigations on these WLM solutions.

Solutions in which stress relaxation is dominated by reptation (high $\mathrm{c}_{\mathrm{s}}$, low R) exhibit relaxation time ratios $\lambda_{\mathrm{e}} / \lambda_{\mathrm{s}}<1$ similar to solutions of covalently bound polymer solutions. This is most likely due to stretching and orientation of the micelles in the strong nonlinear flow during capillary thinning, but further structural investigations are needed to check for additional contributions from chain scission.

In the fast-breaking limit where micelles break and recombine quickly (high $\mathrm{c}_{\mathrm{s}}$, high R) $\lambda_{\mathrm{e}} / \lambda_{\mathrm{s}} \approx 1$ is found. Nonlinear effects seem to be of minor relevance, and the timescale of capillary thinning is solely controlled by linear material parameters available from SAOS. All investigated WLM solutions covering several orders of magnitude in shear modulus $\mathrm{G}_{0}$ and micellar breakage time $\lambda_{\text {br }}$ are found to obey a universal scaling law

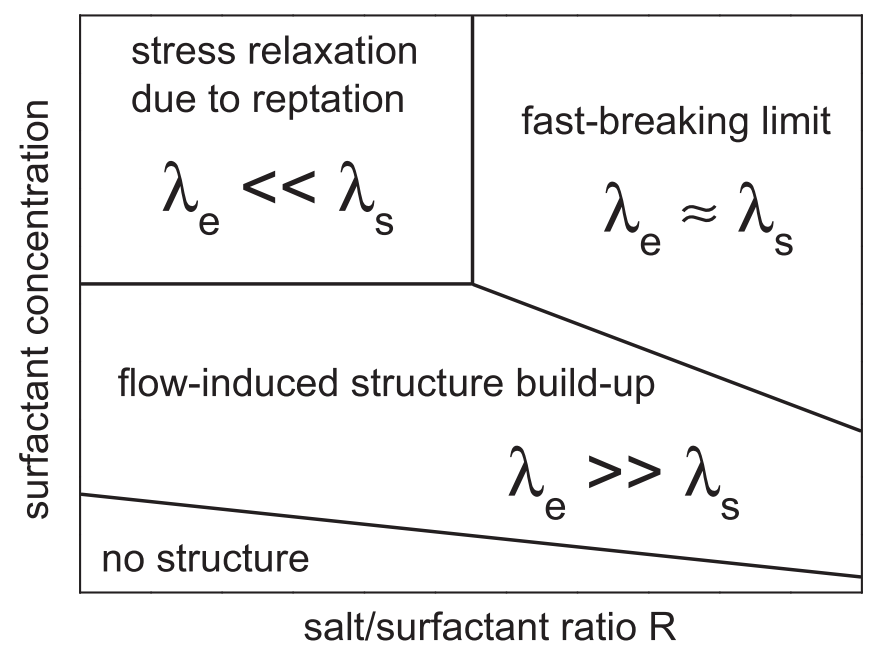

FIG. 13. Schematic phase diagram for WLM solutions with different surfactant concentration and salt/surfactant ratios. 
$\mathrm{t}_{\mathrm{fil}} / \mathrm{G}_{0} \propto \lambda_{\mathrm{br}}^{3 / 2}$ even if $\lambda_{\mathrm{e}} / \lambda_{\mathrm{s}}<1$. These findings indicate that the equilibrium mean length of the micelles does not change during capillary thinning.

Furthermore, CaBER experiments reveal a distinct difference between solutions of linear and branched micelles. The dependence of filament lifetime on zero-shear viscosity is much stronger for linear micelles $\left(\mathrm{t}_{\mathrm{fil}} \propto \eta_{0}^{1.3}\right)$ than for branched micelles $\left(\mathrm{t}_{\mathrm{fil}} \propto \eta_{0}^{0.9}\right)$ and at a given zero-shear viscosity branched micellar solutions exhibit a longer filament lifetime in CaBER experiments than solutions of linear micelles.

At lower surfactant concentrations, filament lifetime is much larger than expected from the corresponding zero-shear viscosity, $t_{\text {fil }} \gg t_{\text {fil, } N}$, and relaxation time ratios $\lambda_{\mathrm{e}} / \lambda_{\mathrm{s}}>1$ are observed. These findings are attributed to an EIS formation and all solutions categorized to show EIS also exhibit SIS build-up. Nevertheless, a minimum zeroshear viscosity $\eta_{0}$ and a minimum initial filament diameter $D_{1}$ are required to achieve such extended filament lifetimes in CaBER experiments indicating EIS. Additionally, FiSER experiments suggest that a minimum total strain $\varepsilon_{\mathrm{L}, \mathrm{c}}$ is needed for structure buildup in extensional flow. Further investigations will have to include birefringence, turbidity and scattering experiments to verify the EIS phenomenon directly and to get a deeper insight into the potentially formed super-micellar structure.

\section{ACKNOWLEDGMENT}

The authors would like to thank Jonathan Rothstein and Sunil Khandavalli (University of Massachusetts) for the possibility to use the FiSER setup and especially for all help given.

\section{References}

Abezgauz, L. R. O., and Danino, D., Department of Biotechnology and Food Engineering, Technion, Haifa, Israel, European Colloid and Interface Society, Geneva, 2007.

Anna, S. L., and G. H. McKinley, "Elasto-capillary thinning and breakup of model elastic liquids," J. Rheol. 45, 115-138 (2001).

Anna, S. L., G. H. McKinley, D. A. Nguyen, T. Sridhar, S. J. Muller, J. Huang, and D. F. James, “An interlaboratory comparison of measurements from filament stretching rheometers using common test fluids," J. Rheol. 45, 83-114 (2001).

Arnolds, O., H. Buggisch, D. Sachsenheimer, and N. Willenbacher, "Capillary breakup extensional rheometry (CaBER) on semi-dilute and concentrated polyethyleneoxide (PEO) solutions," Rheol. Acta 49, 1207-1217 (2010).

Arora, K., R. Sureshkumar, M. P. Scheiner, and J. L. Piper, "Surfactant-induced effects on turbulent swirling flows," Rheol. Acta 41, 25-34 (2002).

Azzouzi, H., J. P. Decruppe, S. Lerouge, and O. Greffier, "Temporal oscillations of the shear stress and scattered light in a shear-banding-shear-thickening micellar solution,” Eur. Phys. J. E 17, 507-514 (2005).

Bazilevsky, A. V., V. M. Entov, and A. N. Rozhkov, "Liquid filament microrheometer and some of its applications," Proceedings of Third European Rheology Conference, Edinburgh, 1990.

Bazilevsky, A. V., V. M. Entov, and A. N. Rozhkov, "Breakup of an Oldroyd liquid bridge as a method for testing the rheological properties of polymer solutions,” Polym. Sci. Ser. A 43, 716-726 (2001).

Beaumont, J., N. Louvet, T. Divoux, M. A. Fardin, H. Bodiguel, S. Lerouge, S. Manneville, and A. Colin, “Turbulent_ows in highly elastic wormlike micelles," Soft Matter 9(3), 735-749 (2013).

Berret, J.-F., D. C. Roux, and P. Lindner, "Structure and rheology of concentrated wormlike micelles at the shear-induced isotropic-nematic transition,” Eur. Phys. J. B 5, 67-77 (1998).

Berret, J.-F., J. Appell, and G. Porte, "Linear rheology of entangled wormlike micelles," Langmuir 9, 2851-2854 (1993). 
Berret, J.-F., S. Lerouge, and J. P. Decruppe, "Kinetics of the shear-thickening transition observed in dilute surfactant solutions and investigated by flow birefringence," Langmuir 18, 7279-7286 (2002).

Berret, J.-F., and Y. Serero, "Evidence of shear-induced fluid fracture in telechelic polymer networks," Phys. Rev. Lett. 87, 048303 (2001).

Bhardwaj, A., D. Richter, M. Chellamuthu, and J. P. Rothstein, "The effect of preshear on the extensional rheology of wormlike micelle solutions," Rheol. Acta 46, 861-875 (2007a).

Bhardwaj, A., E. Miller, and J. P. Rothstein, "Filament stretching and capillary breakup extensional rheometry measurements of viscoelastic wormlike micelle solutions,” J. Rheol. 51, 693-719 (2007b).

Boltenhagen, P., Y. T. Hu, E. Matthys, and D. J. Pine, "Observation of bulk phase separation and coexistence in a sheared micellar solution,” Phys. Rev. Lett. 79, 2359 (1997).

Britton, M. M., and P. T. Callaghan, “Two-phase shear band structures at uniform stress,” Phys. Rev. Lett. 78, 4930-4933 (1997).

Britton, M. M., and P. T. Callaghan, "Shear banding instability in worm-like micellar solutions," Eur. Phys. J. B 7, 237-249 (1999).

Callaghan, P. T., M. E. Cates, C. J. Rofe, and J. B. A. F. Smeulders, "A study of the 'spurt effect' in wormlike micelles using nuclear magnetic resonance microscopy,” J. Phys. II 6, 375-393 (1996).

Cappelaere, E., R. Cressely, R. Makhloufi, and J. P. Decruppe, "Temperature and flow-induced viscosity transitions for CTAB surfactant solutions," Rheol. Acta 33, 431-437 (1994).

Chellamuthu, M., and J. P. Rothsteina, "Distinguishing between linear and branched wormlike micelle solutions using extensional rheology measurements," J. Rheol. 52, 865-884 (2008).

Chen, C., and G. G. Warr, "Light scattering from wormlike micelles in an elongational flow," Langmuir 13, 1374-1376 (1997).

Christanti, Y., and L. M. Walker, "Surface tension driven jet break up on strain-hardening solutions," J. NonNewton Fluid Mech. 100, 9-26 (2001a).

Clasen, C., "Capillary breakup extensional rheometry of semi-dilute polymer solutions," K-A Rheol. J. 22, 331-338 (2010).

Clasen, C., J. P. Plog, W.-M. Kulicke, M. Owens, C. Macosko, L. E. Scriven, M. Verani, and G. H. Mckinley, "How dilute are dilute solutions in extensional flows?," J. Rheol. 50(6), 849-881 (2006).

Clausen, T. M., P. K. Vinson, J. R. Minter, H. T. Davis, Y. Talmon, and G. Miller, "Viscoelastic micellar solutions: Microscopy and rheology," J. Phys. Chem. 96, 474-484 (1992).

Crassous, J. J., R. Regisser, M. Ballauff, and N. Willenbacher, "Characterization of the viscoelastic behavior of complex fluids using the piezoelastic axial vibrator," J. Rheol. 49, 851-863 (2005).

Cressely, R., and V. Hartmann, "Rheological behavior and shear thickening exhibited by aqueous CTAB micellar solutions,” Eur. Phys. J. B 6, 57-62 (1998).

Croce, V., T. Cosgrove, G. Maitland, T. Hughes, and G. Karlsson, "Rheology, cryogenic transmission electron spectroscopy, and small-angle neutron scattering of highly viscoelastic wormlike micellar solutions," Langmuir 19(20), 8536-8541 (2003).

Cromer, M., P. L. Cook, and G. H. McKinley, "Extensional flow of wormlike micellar solutions," Chem. Eng. Sci. 64, 4588-4596 (2009).

Danino, D., “Cryo-tem of soft molecular assemblies," Curr. Opin. Colloid Interface Sci. 17(6), 316-329 (2012).

Danino, D., A. Bernheim-Groswasser, and Y. Talmon, "Digital cryogenic transmission electron microscopy: An advanced tool for direct imaging of complex fluids," Colloids Surf. A 183, 113-122 (2001).

Danino, D., Y. Talmon, and R. Zana, "Cryo-tem of thread-like micelles: On-the-grid microstructural transformations induced during specimen preparation," Colloids Surf. A 169, 67-73 (2000).

Decruppe, J. P., and A. Ponton, "Flow birefringence, stress optical rule and rheology of four micellar solutions with the same low shear viscosity," Eur. Phys. J. E 10, 201-207 (2003).

Dehmoune, J., J. P. Decruppe, O. Greffier, and H. Xu, "Rheometric and rheo-optical investigation on the effect of the aliphatic chain length of the surfactant on the shear thickening of dilute wormlike micellar solutions," Rheol. Acta 46, 1121-1129 (2007).

Dehmoune, J., J. P. Decruppe, O. Greffier, H. Xu, and P. Lindner, "Shear thickening in three surfactants of the alkyl family CnTAB: Small angle neutron scattering and rheological study," Langmuir 25, 7271-7278 (2009). 
Entov, V. M., and E. J. Hinch, "Effect of a spectrum of relaxation times on the capillary thinning of a filament of elastic liquid," J. Non-Newtonian Fluid Mech. 72, 31-53 (1997).

Fardin, M. A., and S. Lerouge, "Instabilities in wormlike micelle systems from shearbanding to elastic turbulence,” Eur. Phys. J. E 35, 91 (2012).

Fardin, M. A., T. Divoux, M. A. Guedeau-Boudeville, I. Buchet-Maulien, J. Browaeys, G. H. McKinley, S. Manneville, and S. Lerouge, "Shear-banding in surfactant wormlike micelles: Elastic instabilities and wall slip," Soft Matter 8(8), 2535-2553 (2012a).

Fardin, M. A., T. J. Ober, C. Gay, G. Gregoire, G. H. McKinley, and S. Lerouge, "Criterion for purely elastic Taylor-Couette instability in the flows of shear-banding fluids," EPL 96(4), 44004 (2011).

Fardin, M. A., T. J. Ober, V. Grenard, T. Divoux, S. Manneville, G. H. McKinley, and S. Lerouge, "Interplay between elastic instabilities and shear-banding: Three categories of Taylor-Couette flows and beyond," Soft Matter 8(39), 10072-10089 (2012b).

Fischer, E., and P. T. Callaghan, "Shear banding and the isotropic-to-nematic transition in wormlike micelles," Phys. Rev. E 64, 011501 (2001).

Fischer, P., and H. Rehage, "Non-linear flow properties of viscoelastic surfactant solutions," Rheol. Acta 36, 13-27 (1997).

Fischer, P., E. K. Wheeler, and G. G. Fuller, "Shear-banding structure orientated in the vorticity direction observed for equimolar micellar solution," Rheol. Acta 41, 35-44 (2002).

Fischer, P., G. G. Fuller, and Z. Lin, "Branched viscoelastic surfactant solutions and their responses to elongational flow," Rheol. Acta 36, 632-638 (1997).

Germann, N., L. P. Cook, and A. N. Beris, "Nonequilibrium thermodynamic modeling of the structure and rheology of concentrated wormlike micellar solutions," J. Non-Newtonian Fluid Mech. 196, 51-57 (2013).

Gier, S., and C. Wagner, "Visualization of the flow profile inside a thinning filament during capillary breakup of a polymer solution via particle image velocimetry and particle tracking velocimetry," Phys. Fluids 24, 053102 (2012).

Hadri, F., and S. Guillou, "Drag reduction by surfactant in closed turbulent flow,” Int. J. Eng. Sci. Technol. 2, 6876-6879 (2010).

Hartmann, V., and R. Cressely, "Influence of sodium salicylate on the rheological behaviour of an aqueous CTAB solution,” Colloids Surf. A 121, 151-162 (1997a).

Hartmann, V., and R. Cressely, "Shear thickening of an aqueous micellar solution of cetyltrimethylammonium bromide and sodium tosylate," J. Phys. II 7, 1087-1098 (1997b).

Hartmann, V., and R. Cressely, "Simple salts effects on the characteristics of the shear thickening exhibited by an aqueous micellar solution of CTAB/NaSal," Europhys. Lett. 40, 691-696 (1997c).

Hartmann, V., and R. Cressely, "Occurrence of shear thickening in aqueous micellar solutions of CTAB with some added organic counterions,” Colloid Polym. Sci. 276, 169-175 (1998).

Haward, S. J., and G. H. McKinley, "Stagnation point flow of wormlike micellar solutions in a microfluidic cross-slot device: Effects of surfactant concentration and ionic environment," Phys. Rev. E 85, 031502 (2012).

Helgeson, M. E., T. K. Hodgdon, E. W. Kaler, and N. J. Wagner, "A systematic study of equilibrium structure, thermodynamics, and rheology of aqueous ctab/nano3 wormlike micelles,” J. Colloid Interface Sci. 349(1), 1-12 (2010).

Herle, V., J. Kohlbrecher, B. Pfister, P. Fischer, and E. J. Windhab, “Alternating vorticity bands in a solution of wormlike micelles,” Phys. Rev. Lett. 99, 158302 (2007).

Herle, V., P. Fischer, and E. J. Windhab, "Stress driven shear bands and the effect of confinement on their structures: A rheological, flow visualization, and rheo-SALS study," Langmuir 21, 9051 (2005).

Hoffmann, S., A. Rauscher, and H. Hoffmann, "Shear-induced micellar structures," Ber. Bunsenges. Phys. Chem. 95, 153 (1991).

Hu, Y., and E. F. Matthys, "Characterization of micellar structure dynamics for a drag reducing surfactant solution under shear: Normal stress studies and flow geometry effects," Rheol. Acta 34, 450-460 (1995).

Hu, Y., C. V. Rajaram, S. Q. Wang, and A. M. Jamieson, "Shear thickening behavior of a rheopectic micellar solution: Salt effects," Langmuir 10, 80-85 (1994). 
Hu, Y. T., P. Boltenhagen, and D. J. Pine, "Shear thickening in low concentration solutions of wormlike micelles I. Direct visualization of transient behavior and phase transitions," J. Rheol. 42, 1185-1208 (1998).

Humbert, C., and J. P. Decruppe, "Flow birefringence and stress optical law of viscoelastic solutions of cationic surfactants and sodium salicylate,” Eur. Phys. J. B 6, 511-518 (1998).

Kadoma, I. A., C. Ylitalo, and J. W. van Egmond, "Structural transitions in wormlike micelles," Rheol. Acta. 36, 1-12 (1997).

Kadoma, I. A., and J. W. van Egmond, "Flow-induced nematic string phase in semidilute wormlike micelle solutions,” Phys. Rev. Lett. 80, 5679-5682 (1998).

Kato, M., T. Takahashi, and M. Shirakashi, "Steady planar elongational viscosity of ctab/nasal aqueous solutions measured in a 4-roll mill flow cell,” J. Soc. Rheol., Jpn. 30, 283-287 (2002).

Kato, M., T. Takahashi, and M. Shirakashi, "Flow-induced structure change and flow instability of ctab/nasal aqueous solution in 4-roll mill flow cell," International Congress on Rheology, Seoul, Korea, (2004).

Kato, M., T. Takahashi, and M. Shirakashi, "Influence of planar elongation strain on flow-induced structure and flow instability of CTAB/NaSal aqueous solution,” Trans. Jpn. Soc. Mech. Eng. Ser. B 72, 1935-1942 (2006).

Kim, G., H. Yoon, and Y. Park, "Drug release from various thicknesses of layered mats consisting of electrospun polycaprolactone and polyethylene oxide micro/nanofibers," Appl. Phys. A 100, 1197-1204 (2010).

Klein, C. O., I. F. Naue, J. Nijman, and M. Wilhelm, "Addition of the force measurement capability to a commercially available extensional rheometer (CaBER)," Soft Matter 7, 242-257 (2009).

Lerouge, S., M. A. Fardin, M. Argentina, G. Gregoire, and O. Cardoso, "Interface dynamics in shear-banding flow of giant micelles," Soft Matter 4, 1808-1819 (2008).

Li, C. F., Y. Kawaguchi, B. Yu, J. J. Wei, and K. Hishida, “ Experimental study of drag-reduction mechanism for a dilute surfactant solution flow,” Int. J. Heat Mass Transfer 51, 835-843 (2008).

Liang, R. F., and M. R. Mackley, " Rheological characterization of the time and strain dependence for polyisobutylene solutions,” J. Non-Newton Fluid Mech. 52, 387-405 (1994).

Liu, C. H., and D. J. Pine, "Shear-induced gelation and fracture in micellar solutions," Phys. Rev. Lett. 77, 2121-2124 (1996).

Lu, B., X. Li, L. E. Scriven, H. T. Davis, Y. Talmon, and J. L. Zakin, "Effect of chemical structure on viscoelasticity and extensional viscosity of drag-reducing cationic surfactant solutions," Langmuir 14, 8-16 (1998).

Lutz-Bueno, V., J. Kohlbrecher, and P. Fischer, "Shear thickening, temporal shear oscillations, and degradation of dilute equimolar CTAB/NaSal wormlike solutions," Rheol. Acta 52, 297-312 (2013).

Mair, R. W., and P. T. Callaghan, "Shear flow of wormlike micelles in pipe and cylindrical Couette geometries as studied by nuclear magnetic resonance microscopy," J. Rheol. 41(4), 901-924 (1997).

McKinley, G. H., "Visco-elasto-capillary thinning and breakup of complex fluid," British Soc. Rheol. HML Report Number 05-P-04, p. 1-49 (2005).

McKinley, G. H., and A. Tripathi, "How to extract the Newtonian viscosity from capilary breakup measurements in a filament rheometer," J. Rheol. 44, 653-670 (2000).

Miller, E., and J. Cooper-White, "The effects of chain conformation in the microfluidic entry flow of polymersurfactant systems," Non-Newtonian Fluid Mech. 160, 22-30 (2009).

Muller, A. J., M. F. Torres, and A. E. Saez, "Effect of the flow field on the rheological behavior of aqueous cetyltrimethylammonium p-toluenesulfonate solutions," Langmuir 20, 3838-3841 (2004).

Münch, C., H. Hoffmann, K. Ibel, J. Kalus, G. Neubauer, U. Schmelzer, and J. Selbach, “Transient small-angle neutron scattering experiments on micellar solutions with a shear-induced structural transition," J. Phys. Chem. 97, 4514-4522 (1993).

Nelson, W. C., H. P. Kavehpour, and C. J. Kim, "A miniature capillary breakup extensional rheometer by electrostatically assisted generation of liquid filaments," Lab Chip 11, 2424-2431 (2011).

Niedzwiedz, K., O. Arnolds, N. Willenbacher, and R. Brummer, "How to characterize yield stress fluids with capillary breakup extensional rheometry (CaBER),” Appl. Rheol. 19, 41969 (2009).

Nowak, M., "Elastic properties of a dilute surfactant solution in the shear-induced state," Rheol. Acta 40, 366-372 (2001).

Oda, R., P. Panizza, M. Schmutz, and F. Lequeux, "Direct evidence of the shear-induced structure of wormlike micelles: Gemini surfactant 12-2-12," Langmuir 13, 6407-6412 (1997). 
Oelschlaeger, C., M. Schopferer, F. Scheffold, and N. Willenbacher, "Linear-to-branched micelles transition: A rheometry and diffusing wave spectroscopy (DWS) study," Langmuir 25, 716-723 (2009).

Oelschlaeger, C., P. Suwita, and N. Willenbacher, "Effect of counterion binding efficiency on structure and dynamics of wormlike micelles," Langmuir 26, 7045-7053 (2010).

Okawara, M., T. Hasegawa, N. Yamada, and T. Narumi, "Experimental study of pressure loss and rheo-optical behavior of CTAB/NaSal aqueous solution under elongational flow," Nihon Reoroji Gakk. 37, 39-46 (2009).

Okawara, M., T. Hasegawa, Y. Iino, and T. Narumi, "Experimental study on pressure loss of CTAB/NaSal aqueous solution through slots and a capillary," Nihon Reoroji Gakk. 36, 137-143 (2008).

Oliveira, M. S. N., R. Yeh, and G. H. McKinley, "Terated stretching, extensional rheology and formation of beads-on-string structures in polymer solutions," J. Non-Newton Fluid Mech. 137, 137-148 (2006).

Ouchi, M., T. Takahashi, and M. Shirakashi, "Shear-induced structure change and flow-instability in start-up Couette flow of aqueous, wormlike micelle solution," J. Rheol. 50, 341-352 (2006a).

Ouchi, M., T. Takahashi, and M. Shirakashi, "Flow-induced structure change and flow-instability of CTAB/ NaSal aqueous solution in a two-dimensional abrupt contract channel," Nihon Reoroji Gakk. 34, 229-234 (2006b).

Padding, J. T., W. J. Briels, M. R. Stukan, and E. S. Boek, "Review of multi-scale particulate simulation of the rheology of wormlike micellar fluids," Soft Matter 5, 4367-4375 (2009).

Papageorgiou, D. T., "On the breakup of viscous liquid threads," Phys. Fluids 7, 1529-1544 (1995).

Pathak, J. A., and S. D. Hudson, "Rheo-optics of equilibrium polymer solutions: Wormlike micelles in elongational flow in a microfluidic cross-slot," Macromolecules 39(25), 8782-8792 (2006).

Perge, C., Fardin, M. A., and Manneville, S., "Surfactant micelles: Model systems for flow instabilities of complex fluids," Eur. Phys. J. E 37, 23 (2014).

Prud'homme, R. K., and G. G. Warr, "Elongational flow of solutions of rodlike micelles," Langmuir 10, 3419-3426 (1994).

Rehage, H., and H. Hoffmann, "Rheological properties of viscoelastic surfactant systems," J. Phys. Chem. 92, 4712-4719 (1988).

Rothstein, J. P., “Transient extensional rheology of wormlike micelle solutions,” J. Rheol. 47, 1227-1247 (2003).

Rothstein, J. P., and G. H. McKinley, "A comparison of the stress and birefringence growth of dilute, semidilute and concentrated polymer solutions in uniaxial extensional flows," J. Non-Newtonian Fluid Mech. 108, 275-290 (2002a).

Rothstein, J. P., and G. H. McKinley, "Inhomogeneous transient uniaxial extensional rheometry," J. Rheol. 46, 1419-1443 (2002b).

Sachsenheimer, D., B. Hochstein, and N. Willenbacher, "Experimental study on the capillary thinning of entangled polymer solutions," Rheol. Acta 53(9), 725-739 (2014).

Sachsenheimer, D., B. Hochstein, H. Buggisch, and N. Willenbacher, "Determination of axial forces during the capillary breakup of liquid filaments-The tilted CaBER method," Rheol. Acta 51, 909-923 (2012).

Salmon, J.-B., A. Colin, S. Manneville, and F. Molino, "Velocity profiles in shear-banding wormlike micelles," Phys. Rev. Lett. 90, 228303 (2003).

Sattler, R., S. Gier, J. Eggers, and C. Wagner, "The final stages of capillary break-up of polymer solutions," Phys. Fluids 24, 023101 (2012).

Schmitt, V., C. M. Marques, and F. Lequeux, "Shear-induced phase separation of complex fluids: The role of flow-concentration coupling," Phys Rev E 52, 4009-4015 (1995).

Schmitt, V., F. Lequeux, A. Pousse, and D. Roux, "Flow behaviour and shear-induced transition near an isotropic/nematic transition in equilibrium polymers," Langmuir 10, 955-961 (1994).

Schubert, B. A., N. J. Wagner, and E. W. Kaler, "Shear-induced phase separation in solutions of wormlike micelles," Langmuir 20, 3564-3573 (2004).

Shikata, T., H. Hirata, and T. Kotaka, "Micelle formation of detergent molecules in aqueous media 2. Role of free salicylate ions on viscoelastic properties of aqueous cetyltrimethylammonium bromide-sodium salicylate solutions," Langmuir 4, 354-359 (1988).

Takahashi, T., and D. Sakata, "Flow-induced structure change of CTAB/NaSal aqueous solutions in step planar elongation flow," J. Rheol. 55, 225-240 (2011). 
Takahashi, T., N. Yako, and M. Shirakashi, "Relationship between shear-induced structure and optical anisotropy on $\mathrm{CPyCl} / \mathrm{NaSal}$ aqueous solution," Nihon Reoroji Gakk. 29, 27-32 (2001).

Vasquez, P. A., G. H. McKinley, and L. P. Cooka, "A network scission model for wormlike micellar solutions I. Model formulation and viscometric flow predictions," J. Non-Newtonian Fluid Mech. 144, 122-139 (2007).

Vasudevan, M., A. Shen, B. Khomami, and R. Sureshkumar, "Self-similar shear thickening behavior in CTAB/ NaSal surfactant solutions,” J. Rheol. 52, 527-550 (2008).

Vasudevan, M., E. Buse, D. Lu, H. Krishna, R. kalyanaraman, A. Q. Shen, B. Khomami, and R. Sureshkumar, "Irreversible nanogelformation in surfactant solutions by microporous flow," Nature Mater. 9, 436-441 (2010).

Walker, L. M., P. Moldenaers, and J.-F. Berret, "Macroscopic response of wormlike micelles to elongational flow," Langmuir 12, 6309-6314 (1996).

Wheeler, E. K., I. Pilar, and G. G. Fuller, "Structure and rheology of wormlike micelles," Rheol. Acta 35, 139-149 (1996).

Wheeler, E. K., P. Fischer, and G. G. Fuller, "Time-periodic flow induced structures and instabilities in a viscoelastic surfactant solution,” J. Non-Newtonian Fluid Mech. 75, 193-208 (1998).

Wunderlich, I., H. Hoffmann, and H. Rehage, "Flow birefringence and rheological measurements on shearinduced micellar structures," Rheol. Acta 26, 532-542 (1987).

Xue, Z. J., C. A. Corvalan, V. Dravid, and P. E. Sojka, "Breakup of shear-thinning liquid jets with surfactants," Chem. Eng. Sci. 63, 1842-1849 (2008).

Yamamoto, T., and K. Taniguchi, "Emergence of turbid region in startup flow of CTAB/NaSal aqueous solutions between parallel plates," J. Rheol. 56, 245-258 (2012).

Yang, J., "Viscoelastic wormlike micelles and their applications," Curr. Opin. Colloid Interface Sci. 7, 276-281 (2002).

Yesilata, B., C. Clasen, and G. H. McKinley, "Nonlinear shear and extensional flow dynamics of wormlike surfactant solutions," J. Non-Newtonian Fluid Mech. 133, 73-90 (2006).

Ziserman, L., S. R. Raghavan, B. Baser, E. W. Kaler, and D. Danino, "Micellar structure and rheological behavior in mixed surfactant systems," in Annual Scientific Meeting of the Israel Society of Microscopy, Jerusalem, 2004. 